\title{
Growing Evidence for Separate Neural Mechanisms for Attention and Consciousness
}

Alexander Maier ${ }^{1}$ \& Naotsugu Tsuchiya ${ }^{2}$

${ }^{1}$ Department of Psychology, Vanderbilt University, Nashville, TN, USA

${ }^{2}$ Monash University, Melbourne, Australia

\begin{abstract}
Our conscious experience of the world seems to go in lockstep with our attentional focus: we tend to see, hear, taste and feel what we attend to, and vice versa. This tight coupling between attention and consciousness has given rise to the idea that these two phenomena are indivisible. In the late 1950s, the honoree of this special issue, Charles Eriksen, was among a small group of early pioneers that sought to investigate whether a transient increase in overall level of attention (alertness) in response to a noxious stimulus can be decoupled from conscious perception using experimental techniques. Recent years saw a similar debate regarding whether attention and consciousness are two dissociable processes. Initial evidence that attention and consciousness are two separate processes primarily rested on behavioral data. However, the past couple of years witnessed an explosion of studies aimed at testing this conjecture using neuroscientific techniques. Here we provide an overview of these and related empirical studies on the distinction between the neuronal correlates of attention and consciousness, and detail how advancements in theory and technology can bring about a more detailed understanding of the two. We argue that the most promising approach will combine ever evolving neurophysiological and interventionist tools with quantitative, empirically testable theories of consciousness that are grounded in a mathematically formalized understanding of phenomenology.
\end{abstract}

\section{Introduction}

Consciousness and attention are both fascinating and difficult to define. The lack of widely accepted definitions stirs frequent debate in either field of study (Block, 2005; Block et al., 2014; Krauzlis, Bollimunta, Arcizet, \& Wang, 2014; Luo \& Maunsell, 2019; Maunsell, 2015; Michel et al., 2019). For the purpose of this paper, we will define consciousness as subjective (phenomenal) experience. Note that this definition encompasses both levels and contents of consciousness (Bachmann \& Hudetz, 2014; Hohwy, 2009), although we will mainly focus on the latter by examining empirical studies of perceptual experience. Moreover, our definition of consciousness does not rely on behavior, such as whether a particular experience can or does get reported (which some authors have distinguished as "access consciousness" or awareness (Block, 2005)). We will similarly bypass various distinctions of attention by collapsing them into the intuitive notion of mental focus on a particular aspect of information (a wide definition seems justified given recent evidence for a general attention factor (Huang, Mo, \& Li, 2012)). By relying on intuition, our definition of attention thus parallels that of the father of American 
psychology, William James, who famously wrote that "everyone knows what attention is" (James, 1890).

Interestingly, James went on that "focalization, concentration of consciousness are of its essence", suggesting an intricate link between consciousness and attention. In this view attention is consciousness - just more of it. The notion of attention being identical to consciousness is still favored by some (O'Regan \& Noe, 2001). One argument for this view is that attending something seems to amplify consciousness, such as enhancing visual contrast sensitivity and/or perceptual appearance (M. Carrasco, 2011). However, another possible interpretation of this observation is that attention is a different process than consciousness, but interacts with consciousness in a certain way. One such view holds that consciousness is necessary for attention in that attention is a modulation of conscious experience. Thus, some authors argue that attention depends on consciousness. To others it seems similarly intuitive that conscious experience only occurs once we attend to the world around us. In that view, consciousness depends on attention, and not the other way around ( $M$. A. Cohen, Cavanagh, Chun, \& Nakayama, 2012). Finally, there is the view that attention and consciousness can be dissociated from each other (Lamme, 2004). This hypothesis is falsifiable in that it comes with several testable predictions (Koch \& Tsuchiya, 2007), such as that consciousness and attention can occur independently of each other, that the effects of consciousness and attention might go in opposing directions and that the neural substrates supporting each of the two phenomena are separable. This last point shall be the central focus of this review.

\section{Eriksen's pioneering contributions}

As outlined above, the relationship between attention and consciousness has long been a subject of debate. In some ways, this discussion can be traced back to the scientist honored by this special edition, Charles Eriksen and his seminal work on "subception" in the 1950's and 60s. Eriksen was interested in studies where volunteers received electric shocks while nonsense syllables were presented for varying amounts of time. The initial data suggested that whether or not subjects consciously perceived the very briefly presented stimuli, repeated presentations of the same stimuli evoked a galvanic skin response, reminiscent of subjects anticipating the pain (Lazarus \& McCleary, 1951). This phenomenon coined "subception" was seen as evidence that a heightened "arousal" (which, in this context, means a transient increase in alertness or unfocused attention) can be evoked in the absence of conscious perception of the stimulus that caused it (see (Robbins et al., 1998; Thiele, 2013; Tsuchiya \& Koch, 2014) for more on the argument that arousal is closely related to attention; but also see (Otazu, Tai, Yang, \& Zador, 2009)). Eriksen was critical of this interpretation and argued that there were shortcomings of the original study (Eriksen, 1956). As we will discuss below, several of Eriksen's critiques such as that (verbal) reports are limited in determining consciousness (Eriksen, 1960) have re-emerged in recent years. 


\section{Behavioral evidence that attention and consciousness are dissociable}

More than 40 years after Charles Eriksen's investigation of alertness changes in the absence of conscious perception, new empirical work re-emerged that raises similar questions. In fact, the original question as to the relation of alertness and unconscious processing has been expanded and dissected in several ways: 1) Can unconscious stimuli still become the target of top-down attentional selection? 2) Can unconscious stimuli still attract attention in a bottom-up manner? And the focus of this review: 3) What are the neural correlates of unconscious stimuli that interact with attention in certain ways?

Initial evidence for such dissociation between attention and consciousness was provided by a clinical study which showed that neurological patients lacking large parts of primary visual cortex (V1) respond faster when attention is drawn to a stimulus while being unable to consciously see what evoked the change in attentional state (Kentridge, Heywood, \& Weiskrantz, 1999, 2004; Schurger, Cowey, Cohen, Treisman, \& Tallon-Baudry, 2008).

A similarly stunning result was found in split-brain patients whose cerebral hemispheres were surgically separated to treat severe epilepsy (Gazzaniga, 2014). An interesting consequence of the split-brain surgery is that the operated patients seem to report that their visual perception is split in half (but see: (Pinto, de Haan, \& Lamme, 2017; Pinto, Lamme, \& de Haan, 2017; Pinto, Neville, et al., 2017)). When these patients are asked to report their visual experience using either their left or right hand (which are controlled by the right and left hemispheres, respectively), they can only indicate whatever is shown to the left or right visual hemifields. In other words, everything that is to one side of their nose seems to be perceived by only one half of their brain and this side of their brain is completely unaware of what is shown to the other side of their nose (Volz \& Gazzaniga, 2017). And yet, this is not the case for their attentional focus, which can still operate across the entire visual field (Corballis, 1995). For example, attentional cueing experiments found that when spatial cues are presented to either the left or right visual hemifield, performance is identical, suggesting that attention is a unified resource shared between cerebral hemispheres (But also see Alvarez \& Cavanagh 2005 Psych Sci). This finding not only suggests that the neural substrates for consciousness and attention are separable, but that attention may be closely tied to subcortical structures.

This finding in human split brain patients are also consistent with a recent surge of primate electrophysiology research, which points to non-cortical structures, such as the superior colliculus, thalamic pulvinar nucleus, and basal ganglia as critical neural substrates for attention (Arcizet \& Krauzlis, 2018; Bogadhi, Bollimunta, Leopold, \& Krauzlis, 2018; Bollimunta, Bogadhi, \& Krauzlis, 2018; Fiebelkorn \& Kastner, 2020; Halassa \& Kastner, 2017; Krauzlis, Bogadhi, Herman, \& Bollimunta, 2018; Krauzlis et al., 2014; Krauzlis, Lovejoy, \& Zenon, 2013; Saalmann \& Kastner, 2011; Saalmann, Pinsk, Wang, Li, \& Kastner, 2012; Zenon \& Krauzlis, 2012). Attention thus might have a more expansive subcortical basis than previously 
appreciated. Accordingly, severing interhemispheric cortical connections in split brain patients may have less of an impact on attention (which in some ways remains intact) than on conscious perception (which appears to be split in half, or otherwise diminished). However, note that there is also emerging evidence that certain subcortical structures, such as higher order nuclei of the thalamus play a crucial role for both levels as well as contents of consciousness (Donoghue et al., 2019; Redinbaugh et al., 2020; Schmid \& Maier, 2015; Wilke, Mueller, \& Leopold, 2009). Thus, while these novel findings point at dissociable neural processes for attention and consciousness, it is not as simple as attention being a subcortical phenomenon and consciousness a product of the neocortex.

Following up on these seminal studies in the blindsight and split-brain patients, a large number of studies performed on healthy observers established that attention can be captured outside of consciousness (Faivre \& Kouider, 2011; Kentridge, Nijboer, \& Heywood, 2008; Kiefer \& Martens, 2010; Martens, Ansorge, \& Kiefer, 2011; Sumner, Tsai, Yu, \& Nachev, 2006). Based on these and other evidence (for further recent updates, see (Tsuchiya \& Koch, 2016)), largely speaking, there is a strong agreement in the field that consciousness is not necessary for attention, but whether attention is necessary for consciousness continues to be debated (M. A. Cohen et al., 2012; Michael A Cohen, Dennett, \& Kanwisher, 2016; Dehaene, Changeux, Naccache, Sackur, \& Sergent, 2006; vanBoxtel, Tsuchiya, \& Koch, 2010a).

\section{Neuroscientific approaches to study the attention/consciousness divide}

One of the most impactful propositions in recent years that was derived from this empirical work has been the hypothesis that neuronal mechanisms that support consciousness and attention can work independently and be dissociated from each other (Koch \& Tsuchiya, 2007, 2012; Lamme, 2003, 2004). When originally formulated, this hypothesis mostly rested on behavioral data since there were few studies at the time testing for separate neural substrates (but see (Wyart \& Tallon-Baudry, 2008)). This situation has changed drastically during the past years, with several independent groups investigating whether attention and consciousness can be disassociated not only in behavioral terms, but also in their underlying patterns of cortical activation (Nani et al., 2019). This empirical test is important in the attempt to falsify the original dissociation hypothesis: If there were no distinction in the brain activation patterns for attention and consciousness, it seems implausible for attention and consciousness to be supported by distinct neural mechanisms. In what follows, we will review several neuroimaging and neurophysiological studies in order to determine whether or not consensus has emerged across the various experimental approaches taken to date.

\section{fMRI evidence for a separation between consciousness and attention}

Functional magnetic resonance imaging non-invasively yields sub-centimeter localization of brain function across the entire brain. However, this fine-grained global coverage 
comes at the cost of a rather poor temporal resolution of several seconds. Despite these technical limitations, recent $\mathrm{fMRI}$ studies have been pivotal in demonstrating that attention can increase neural response to invisible stimuli. And thanks to the spatial resolution of fMRI, such effects could be located in distinct parts of the brain, such as the visual cortex (e.g., V1) (Watanabe et al., 2011).

fMRI even produced evidence pointing at a double dissociation between attention and consciousness (Kouider, Barbot, Madsen, Lehericy, \& Summerfield, 2016): Whether or not subjects consciously saw a stimulus yielded a larger or smaller fMRI response, respectively. Similarly, whether they attended a stimulus or not (in this particular case, whether they were trying to detect a certain stimulus type or not) produced somewhat smaller changes in fMRI response (Figure 1a - note the difference in units on the ordinate) (Kouider et al., 2016)).

An even more striking dissociation was found after distinguishing between different kinds of attention. There are many different ways in which attention can be elicited, such as a subject's behavioral goals (goal driven, or endogenous attention) or by salient stimulus events (stimulus driven, or exogenous attention). Comparing the whole-brain activation pattern evoked by endogenous attention to the brain activation linked to a threshold stimulus reaching consciousness revealed a surprisingly small overlap in that the thalamus was the only part of the brain that showed a statistical interaction between these two phenomena (Chica, Bayle, Botta, Bartolomeo, \& Paz-Alonso, 2016).

It is also possible to demonstrate the independence of the neuronal mechanisms supporting attention from those supporting consciousness by holding one of them constant and varying the other. Doing so showed that the brain area most strongly modulated in activity by whether or not a visual stimulus reached consciousness (with no change in attentional status) was the temporo-parietal junction (TPJ) (Webb, Igelstrom, Schurger, \& Graziano, 2016). This is an important finding since this part of cortex is more commonly associated with varying attentional rather than conscious state whenever subjects are fully aware of the stimuli (S. W. Han \& Marois, 2014).

\section{EEG/MEG evidence for a separation between consciousness and attention}

In contrast to $\mathrm{fMRI}$, the other widely used non-invasive technique - the electro/magneto-encephalogram (E/MEG) - does not allow for precise localization of neural activity in space. But E/MEG has an exquisite temporal resolution. It thus can provide complementary evidence to $\mathrm{fMRI}$ on the question of attention and consciousness operating independently of each other.

Somatosensory stimulation (touch) of fingers, for example, can be applied to participants right at the threshold of conscious perception. Such weak stimuli are consciously perceived or not, depending on each trial. Under these circumstances, physically identical stimuli evoke a greater EEG response when they produce a conscious touch sensation (Figure 
2a). Subjects then can be tasked to either attend the stimulated fingers or attend elsewhere. If the neural mechanisms supporting attention and consciousness were inseparable, there should be no effect of attention on the EEG response when the stimuli went undetected. Yet, attention increases the EEG magnitude even to unconscious stimuli (Forschack, Nierhaus, Muller, \& Villringer, 2017). In other words, the somatosensory EEG response follows a $2 \times 2$ dissociation (conscious/unconscious vs. attended/unattended) matrix (Figure 2a), similar to what was found across behavioural studies (Tsuchiya \& Koch, 2016).

Analogous work in the visual domain produced similar results (Chica, Lasaponara, Lupianez, Doricchi, \& Bartolomeo, 2010; Wyart \& Tallon-Baudry, 2008). In the study by Wyart and Tallon-Baudry, participants viewed faint visual patterns that hovered around the perceptual threshold, thus consciously seeing it only about half of the time. Critically, in $50 \%$ of trials subjects attended the screen location where the target images were shown and in the other $50 \%$ of trials they attended elsewhere. The authors then compared instances when subjects attended to stimuli which were either seen or unseen, and stimuli which were visible when attended vs. unattended. This study used magnetoencephalography (MEG), which is believed to be more sensitive to deeper (folded) parts of the cortex than EEG. But the pattern of responses differed little between techniques (Figure $\mathbf{2 b}$ ). Even more noteworthy, MEG is sensitive for brain activity across a wide range of frequencies. Thus, this study was able to go beyond investigating the mere magnitude of brain responses. The authors found that consciousness was correlated with changes in low gamma activity $(55-65 \mathrm{~Hz})$ while attention related more to high gamma $(75-90 \mathrm{~Hz})$ frequencies instead (Wyart \& Tallon-Baudry, 2008). A similar spectral dissociation between conscious perception and attention has been found in patients with V1 lesions (Schurger et al., 2008). What is more, there was a difference in onset of the neural activity related to attention and the neural responses correlating with consciousness, with attention lagging conscious perception. Other studies (by the same authors) studying the magnitude of the responses rather than their spectral profile found a similar asynchrony between attention and consciousness, albeit in the reverse order (Wyart, Dehaene, \& TallonBaudry, 2011).

Attention-related EEG components were also observed both when observers consciously experienced attention-directing cues and when they failed to do so (Travis, Dux, \& Mattingley, 2019). However, the magnitude of this attention signal was diminished when the cue was invisible (Figure 1c) (Travis et al., 2019). Several other studies convergingly suggest that attention can modulate EEG responses even if stimuli do not reach consciousness (Kiefer \& Brendel, 2006; Koivisto \& Revonsuo, 2007, 2008; Koivisto, Revonsuo, \& Lehtonen, 2006; Sanchez-Lopez, Savazzi, Pedersini, Cardobi, \& Marzi, 2019; Woodman \& Luck, 2003).

On the flip side, neural correlates of consciousness have been observed independently of attentional state (Boehler, Schoenfeld, Heinze, \& Hopf, 2008; Koivisto et al., 2006). The general pattern emerging from these studies as well as studies that test for a double 
dissociation between attention and consciousness directly, is that both attended and consciously perceived stimuli evoke larger brain responses (Figure 1b). Each of these response enhancements can be evoked in the absence of the other or additively superimposed, with attentional response enhancements being significantly smaller than consciousness-related enhancement (Figure 3a).

Two noteworthy recent EEG studies are opening exciting new directions towards studying the dissociation of attention and consciousness. The first study focused on the dissociation of attention and consciousness in terms of the temporal rhythms at which they operate. Recent evidence suggests that various measures of task performance tend to oscillate at either theta- $(\sim 7 \mathrm{~Hz})$ or alpha- $(\sim 10 \mathrm{~Hz})$ rhythms, implicating a rhythmic structure to perception (VanRullen, 2016), attention (Helfrich et al., 2018; Kienitz et al., 2018; Landau \& Fries, 2012) or both. Davidson and colleagues (Matthew J Davidson, Alais, vanBoxtel, \& Tsuchiya, 2018) investigated whether these temporal rhythms could also be manipulated by cueing attention to either visible or invisible stimuli in a binocular rivalry paradigm (Blake \& Logothetis, 2002; Maier, Panagiotaropoulos, Tsuchiya, \& Keliris, 2012). They found that conscious perceptual reversals during binocular rivalry, when each eye's view is confronted with a drastically different stimulus coincided with a particular temporal rhythm (see also (Cha \& Blake, 2019)). The rate of this temporal rhythm could be selectively influenced by cueing attention to either the visible or invisible visual stimuli (Matthew J Davidson et al., 2018). Simultaneous EEG recordings showed attention-related rhythmic modulations correlated with fronto-parietal activity in the theta-band when attention was cued to the invisible image, consistent with the recently proposed role of the fronto-parietal attention network in exploration, and environmental sampling (Fiebelkorn \& Kastner, 2019). To date, such dissociation between consciousness and attention in the temporal domain are still relatively scarce (but see: (Naccache, Blandin, \& Dehaene, 2002)), but this research line marks a promising future direction, particularly when utilizing the excellent temporal resolution of E/MEG.

The other notable EEG study utilized temporally modulating stimuli to evoke a steadystate visually evoked potential (SSVEP) (Norcia, Appelbaum, Ales, Cottereau, \& Rossion, 2015; Smout \& Mattingley, 2018; Vialatte, Maurice, Dauwels, \& Cichocki, 2010). SSVEP are used to "frequency-tag" stimuli by turning them on an off at distinct flicker frequencies. Since neurons are expected to respond in synchrony with the on- and offsets of flickering stimuli, this frequency tagging improves the stimulus-selectivity of EEG responses by characterizing stimulus-specific neural responses in the frequency-domain. Critically, the strength of SSVEPs have been used extensively as a correlate of both the focus of attention without overt responses (Morgan, Hansen, \& Hillyard, 1996; Muller et al., 2006), as well as the contents of consciousness during changes in perception (Brown \& Norcia, 1997; Lansing, 1964). 
Davidson and colleagues (Matthew J Davidson, Mithen, Hogendoorn, van Boxtel, \& Tsuchiya, 2020) adapted a display where SSVEP stimuli faded from view due to visual adaptation (see also (M. J. Davidson, Graafsma, Tsuchiya, \& van Boxtel, 2020; Schieting \& Spillmann, 1987; Weil, Kilner, Haynes, \& Rees, 2007)). Intriguingly, this perceptual fading is known to be enhanced by attention, in that attending to flickering stimuli results in more rapid and more frequent disappearance (DeWeerd, Smith, \& Greenberg, 2006; Lou, 1999). This remarkable "negative" effect of attention on consciousness has been also reported for other phenomena, such as motion induced blindness (Geng, Song, Li, Xu, \& Zhu, 2007; Scholvinck \& Rees, 2009) and negative afterimages (J. W. Brascamp, van Boxtel, Knapen, \& Blake, 2010; Lou, 2001; Suzuki \& Grabowecky, 2003; vanBoxtel, Tsuchiya, \& Koch, 2010b). Davidson et al. found that perceptual fading of the flickering stimulus was accompanied by an increase of the SSVEP signal at the frequency which tagged the disappearing stimulus. At the same time, alpha-band activity $(8-12 \mathrm{~Hz})$, whose diminishment is commonly seen as an index of the attentional orienting (D'Andrea et al., 2019; Gould, Rushworth, \& Nobre, 2011; Horschig, Oosterheert, Oostenveld, \& Jensen, 2015; Jensen, Gips, Bergmann, \& Bonnefond, 2014; Spaak, Bonnefond, Maier, Leopold, \& Jensen, 2012), decreased at the time of target disappearance. This study raises an interesting question regarding two common assumptions about consciousness and attention. First, given that target disappearance increased the strength of stimulus-specific neural responses, the notion that consciousness is always accompanied by enhanced neuronal responses needs to be refined (see also (Merten \& Nieder, 2012) and next section). Second, previous SSVEP experiments that aimed to tag the neural correlates of consciousness (Brown \& Norcia, 1997; Tononi, Srinivasan, Russell, \& Edelman, 1998) might have inadvertently tagged the neural correlates of attention instead (see also (P. Zhang, Jamison, Engel, He, \& He, 2011)).

These new advances in empirical studies are prompting a revision of the theoretical models of consciousness (see below).

\section{Single neuronal activity correlates with attention and consciousness in a distinct manner}

All of the studies summarized so far were based on non-invasive techniques that can readily be used for human subjects, yet lag either in temporal or spatial resolution. One way to circumvent these methodological constraints is to resort to invasive techniques in animal models. Non-human primates in particular offer phylogenetic (and thus neuroanatomical) closeness (Dougherty, Schmid, \& Maier, 2018; Kaas, 2012a, 2012b, 2013), the ability to apply complex (non-verbal) cognitive tasks suited for the study of attention (Bosman et al., 2012; Luck, Chelazzi, Hillyard, \& Desimone, 1997; Maunsell, 2015; Mitchell, Sundberg, \& Reynolds, 2009; Pooresmaeili, Poort, Thiele, \& Roelfsema, 2010) and consciousness (D. A. Leopold, Maier, \& Logothetis, 2003) as well as a greater spectrum of invasive techniques, such as the neurophysiological measurement of action potentials that can be linked back to one or more brain cells (Roelfsema \& Treue, 2014). One of the downsides of choosing this approach is the 
associated cost in labor-intensive work that results in long time spans from experimental planning to data collection and analysis (typically years). Perhaps as a result of this, we are not aware of any published neurophysiological studies that examined neuronal activity related to consciousness and attention while manipulating both independently of each other. There is, however, a large body of studies that examined each of these phenomena in isolation (e.g., Figure 3b).

Interestingly, the single neuron data collected in animals parallels the human studies summarized above in that they suggest that i) both attention and consciousness correlate with increased brain activity and ii) consciousness correlates with a bigger increase in brain activity compared to attention (Figure $\mathbf{3 b}$ ). Indeed, most studies studying either phenomenon in isolation found a similar general trend of enhanced neuronal responses across both cortical and subcortical structures when subjects are conscious (as opposed to unconscious) of a sensory stimulus (Mashour, Roelfsema, Changeux, \& Dehaene, 2020; Noy et al., 2015). When a stimulus is attended, similar, but more modest boosts in neuronal responses are typically observed. (Maunsell, 2015). However, this is not always the case. Recent work demonstrated that under some circumstances, the exact opposite can be found (Matthew J Davidson, Mithen, Hogendoorn, vanBoxtel, \& Tsuchiya, 2020; Merten \& Nieder, 2012).

One way to explain these apparent discrepancies are regional differences in the brain. For example, while reward tends to elevate spiking responses across most of the neocortex, including most visual cortical areas, area V4 seems to show the inverse pattern. At least during some tasks, whenever subjects learn that they will be receiving reward, V4 neurons undergo profound suppression (the larger the expected reward, the deeper the suppression)(Shapcott et al., 2020). This see-saw pattern of neuronal responses is also seen on a larger scale for the socalled default mode network. Generally speaking, neuronal activity increases across a wide array of cortical areas when subjects engage in a task (e.g., (Lundqvist, Bastos, \& Miller, 2020)). In contrast, the default mode network, a collection of distinct frontal and parietal regions, are more active when a subject is resting idly compared to being actively engaged in a task (Hayden, Smith, \& Platt, 2009; Raichle, 2015).

A final consideration is that attention-related increases in spiking magnitude are only part of the story. Attentional selection is further accompanied by changing levels of neuromodulators (Thiele, 2013), neural synchrony and/or oscillatory activity (Bosman et al., 2012; Ruff \& Cohen, 2014) and changes in effective connectivity (vanKempen et al., 2020). While there is some paralleling evidence (Sewards \& Sewards, 2001), less is known about the role of these phenomena for consciousness

\section{Future research promises a more granular dissection of consciousness and attention}

By focusing on tractable questions, the neuroscience of consciousness has made tremendous advances during the past two decades (Boly et al., 2013; Koch, Massimini, Boly, \& 
Tononi, 2016; Mashour et al., 2020). One of these questions that seems close to consensus is whether conscious perception and selective attention are supported by two distinct brain mechanisms. Both the behavioral as well as the neuroscientific evidence, as reviewed in this article, leans increasingly towards the affirmative. The neural responses related to attention and consciousness seem distinct in magnitude, spectral properties and at least to some degree in their spatial extent across the brain. Yet, several open questions remain. Among these questions is how the neural correlates of consciousness and attention differ between different parts of the brain. Exactly which neural structures are involved in giving rise to consciousness and attention is still unclear, especially when moving from a more global perspective to the scale of neural circuits and cell types. This question is unlikely to be answered using noninvasive techniques which are limited in either spatial or temporal resolution.

\section{Outlook1: Technological developments for further refining our understanding of the neuronal substrates of consciousness and attention}

Two recent developments are particularly promising in that regard. First, thanks to the success of deep brain stimulation, there is an ever-increasing number of people who live for extended periods of time with chronic electrode implants in their brains. This development goes hand-in-hand with invasive neurophysiological recordings that provide resolution at the level of single neurons becoming increasingly commonplace in human neurological patients (Aquino et al., 2020; Isik, Singer, Madsen, Kanwisher, \& Kreiman, 2018; Kreiman, Koch, \& Fried, 2000; Pryluk, Kfir, Gelbard-Sagiv, Fried, \& Paz, 2019; Rees, Kreiman, \& Koch, 2002; Rutishauser et al., 2013; Rutishauser et al., 2015). Given this trend, it seems increasingly likely that we are facing a future where neurophysiological implants are used in healthy individuals (Musk, 2019).

A second, related, technological breakthrough is the rapid ascent of silicone-based microelectrode arrays that provide real-time microscopic (i.e., single-neuron) resolution across several centimeters (Jun, Steinmetz, Siegle, Denman, Bauza, Barbarits, Lee, Anastassiou, Andrei, Aydin, Barbic, Blanche, Bonin, Couto, Dutta, Gratiy, Gutnisky, Hausser, Karsh, Ledochowitsch, Lopez, Mitelut, Musa, Okun, Pachitariu, Putzeys, Rich, Rossant, Sun, Svoboda, Carandini, Harris, Koch, O'Keefe, et al., 2017; Musk, 2019; Steinmetz, Koch, Harris, \& Carandini, 2018). In other words, thanks to modern electrode design and technology together with advances in computing power, big data storage and machine learning-based analyses (Pachitariu, Steinmetz, Kadir, Carandini, \& Harris, 2016), it has become feasible to simultaneously record thousands of neurons across a wide array of subcortical and cortical areas (Jun, Steinmetz, Siegle, Denman, Bauza, Barbarits, Lee, Anastassiou, Andrei, Aydin, Barbic, Blanche, Bonin, Couto, Dutta, Gratiy, Gutnisky, Hausser, Karsh, Ledochowitsch, Lopez, Mitelut, Musa, Okun, Pachitariu, Putzeys, Rich, Rossant, Sun, Svoboda, Carandini, Harris, Koch, O'Keefe, et al., 2017; Musk, 2019; Steinmetz et al., 2018; Steinmetz, Zatka-Haas, Carandini, \& Harris, 2019; Stringer, 
Pachitariu, Steinmetz, Carandini, \& Harris, 2019). It is hard to overestimate the quantum leap that has been achieved using this approach (Figure 4).

Up until now, as we reviewed in the above sections for E/MEG and $\mathrm{fMRI}$, neuroimaging techniques have sacrificed either spatial or temporal resolution when trying to cover the entire brain. Only by substantially limiting the spatial coverage, electrophysiological measures were able to get to the resolutions of single neurons. Thanks to these new electrode arrays, we can now study single neuron activity across large parts of the brain with sub-millisecond resolution. More than that, due to the large number (hundreds to thousands) and high spatial resolution (less than tens of microns) of electrodes on these silicon probes, the spiking activity of hundreds of neurons recorded simultaneously can now be sampled in a 2D spatial mosaic consisting of multiple adjacent microelectrodes. The resulting spatial profile of action potentials can be used to create an "electromorphological" fingerprint to identify and classify different neuron types using in vivo extracellular neurophysiology in a previously unprecedented way (Jia et al., 2019).

So, what do these technological advances offer for our understanding of the neural basis of consciousness and attention? The massive increase in electrode count currently underway in the field of neurophysiology is more than just a quantitative advance, but it marks the dawn of a qualitatively new advance in assessing brain activity. The implications are manifold, but immediately apparent for the question at the heart of this review. Both consciousness and attention arise from the activity of neurons that are widely dispersed across the brain. Whether neurons that support these phenomena differ biochemically (or not (Maier, Logothetis, \& Leopold, 2007)), morphologically, or in any other physical characteristic from neighboring neurons is still unknown, as is the question of how far the neural populations supporting consciousness and attention overlap. More importantly, rather than being limited to studying isolated neurons, neurophysiology is now entering a phase where entire neural circuits, spanning cortical layers, areas and nuclei are measured without sacrificing either spatial or temporal resolution (i.e., we are now studying brain activity at the macro- and mesoscale with microscale resolution).

With this technological advance, comes increased need for a quantitative theory of consciousness and attention. We particularly need a theory that not only manages to explain the conceptual advances outlined above, but that can also provide empirically testable and non-trivial (e.g., counterintuitive) predictions on consciousness and attention. Such theoretical guidance will promote the targeted and theory-driven data collection to specifically test hypotheses on the brain mechanisms of consciousness and attention. With a successful marriage of theory and empirical experiments, we are poised to gain unprecedented new insight in these phenomena at the neuronal circuit-level (see below). 


\section{Outlook 2: Developments towards an empirically-testable quantitative science of phenomenology}

To make real progress in our scientific understanding of the neural basis of consciousness and how it relates to attention, we will also need to make conceptual breakthroughs at a level comparable to the above-mentioned technological breakthroughs. For example, it seems likely that the full potential of these new invasive neuroscientific techniques will be (at least initially) primarily available in animals. Therefore, we urgently need to develop improved experimental paradigms that can distinguish consciousness and attention in the absence of verbal communication, such as no-report paradigms (Frassle, Sommer, Jansen, Naber, \& Einhauser, 2014; D. A. Leopold et al., 2003; Tsuchiya, Wilke, Frassle, \& Lamme, 2015; Wilke et al., 2009). Indeed, studies that eliminated overt behavioral reports during experimental investigations of conscious perception have revealed that part of what have previously been deemed the neural correlates of consciousness (NCC) may actually be brain activity related to the planning and execution of behavioral reports (Aru, Bachmann, Singer, \& Melloni, 2012; DeGraaf, Hsieh, \& Sack, 2012; Tsuchiya et al., 2015). This has been an important step in narrowing down which neural responses are truly consciousness-related, as there are arguably many additional processes that are engaged in the brain, once, and only if, consciousness has changed (attention being one of them). The no-report approach to eliminating downstream processes of the NCC thus is in some way comparable to the use of bistable (also called multistable) stimuli, which allows researchers to keep sensory stimulation constant while perception varies in order to eliminate low-level responses upstream of the NCC (J. Brascamp, Sterzer, Blake, \& Knapen, 2018; Frith, Perry, \& Lumer, 1999; Lumer, Friston, \& Rees, 1998).

No report paradigms have raised interesting questions regarding the relationship between attention and consciousness (M. A. Cohen, Ortego, Kyroudis, \& Pitts, 2020; Frassle et al., 2014; Montemayor \& Haladjian, 2019; Wilke et al., 2009). For example, eliminating report also challenges whether the (low frequency) gamma activity that has been associated with consciousness might be related to post-perceptual decision making and/or motor planning instead (Pitts, Padwal, Fennelly, Martinez, \& Hillyard, 2014). No report paradigms pose certain challenges for experiments that seek to dissociate attention from consciousness in that report is often used to control attentional state. It thus has been difficult so far to combine both approaches. Future experiments will likely fill this increasingly pressing knowledge gap.

Another consideration is that, while animal studies with massive neural recordings and more sophisticated behavioral paradigms will undoubtedly play a critical role in advancing our understanding of the neural mechanisms of consciousness and attention, human studies will also need to become more quantitatively sophisticated to promote our understanding of the structure of conscious phenomenology. In general, consciousness researchers painfully know how little we understand the structure of consciousness, but this issue has been largely 
neglected in the last decades due to the immense advance in the side of neuroscience of consciousness. Indeed, we foresee further developments of psychophysics, incorporating the latest technological advancements (M. A. Cohen, Botch, \& Robertson, 2020) as well as ideas from philosophical approaches invented by Husserlian phenomenology (Varela, 1996; Zahavi \& Gallagher, 2008).

A particularly exciting promising development in this regard is the rapidly emerging research program that aims to uncover and mathematically formalize isomorphisms between the structure of conscious phenomenology and the structure of information that is inherent in neuronal activity (Figure 5). While there is a surface resemblance to studies that aim to uncover the NCC, this new line of research adds emphasis on structure (i.e., relative distances of states in both experiential and neuronal space). For example, a common approach to test whether a particular set of neurons belonged to the NCC is to keep sensory inputs constant while phenomenology is changing (Frith et al., 1999). This paradigm has been successfully applied to determine whether certain neurons and what aspect of neuronal responses correlate with consciousness (see (D. A. Leopold \& Logothetis, 1999; Michel et al., 2019; Parker \& Newsome, 1998) for review). The promising next step is to focus on the structural relations that exist within phenomenology, such as the phenomenon that tones of certain frequency ratios (e.g., musical notes of the same chroma (Shepard, 1982) ) sound more similar than other tones or the fact that visual stimuli are located relative to each other in visual space. This novel approach subsumes prior work on the NCC, and extends that line of research to study different sensory inputs that evoke similar phenomenology, such as short and long wavelengths of light evoking the perception of purple and red, which are phenomenologically more similar than the colors evoked by physically more similar wavelengths.

Figure 5 provides a conceptual schematic for this approach. For example, the phenomenological relationship between two types of sounds (e.g., C major chords), and the relationships among various other sounds (as well as conscious sensations in other modalities) can be quantified and mathematically expressed in a multidimensional space through largescale similarity rating experiments and other yet-to-be developed techniques. The derived mathematical structure of certain types of phenomenological experience (here the helix of musical "chroma" that symbolizes the relationship between sounds of different pitch that makes them appear "similar but different") will serve as a reference (Figure 5, upper row). At the same time, connectivity and activity states of the neural networks that give rise to this conscious experience need to be measured, mathematically quantified and characterized (Figure 5, bottom row).

It seems parsimonious to assume that a close relationship between two phenomenological states arises from similar closeness of underlying neuronal states. In other words, on some level there should be an isomorphic relationship between the (differences in) neuronal space and the (differences in) phenomenological space - two sounds that sound 
similar are accompanied by similar neural activity. However, neither of these two spaces seem to be simple, Euclidian vector spaces. Phenomenological space does not seem to follow the rules of geometric space: Even just considering these similarity relations, the abstracted phenomenological structure of consciousness may not be sufficiently represented by a simple geometric model (e.g., a multi-dimensional vector space)(Gärdenfors, 2000) as similarity relations are known to violate axioms of distances. One example of this phenomenon is an asymmetrical relationship in similarity judgements (Hodgetts \& Hahn, 2012; Palmer, 1999; Polk, Behensky, Gonzalez, \& Smith, 2002; Pothos, Busemeyer, \& Trueblood, 2013; Tversky, 1977). Such asymmetry in relationships severely violates the axioms of distances, strongly suggesting that underling phenomenal structure cannot be captured by a simple geometric model. In that sense, the phenomenological structure mapped by this new approach might necessitate more flexible and abstract mathematical tools, such as topology and category theory (A. Haun \& Tononi, 2019; Prentner, 2019; Tsuchiya \& Saigo, 2020).

At the same time, the similarity in neural activation giving rise to similar experiences cannot simply be measured in physical space (including transformations such as the Talairach reference brain space): Two observers having the same conscious experience will not have the exact same 3D activation pattern in their brains (even monozygotic twins have anatomically distinct brains, with different gyri and sulci (Lohmann, Von Cramon, \& Steinmetz, 1999)). Thus, some kind of abstraction is necessary to find the specific aspect of brain activity that is isomorphic to the structure of phenomenology. One promising idea is to mathematically extract the informational structure that is inherent in neuronal activity (Figure 5, bottom row). A particularly promising analytical approach in this regard is provided by the Integrated Information Theory (IIT) of consciousness proposed by Tononi (Tononi, 2004). Recent advances of IIT have culminated in the development of algorithms to empirically derive (accurate proxies of) informational structures from neural recordings (Barrett \& Seth, 2011; A. M. Haun et al., 2017; Leung, Cohen, Van Swinderen, \& Tsuchiya, 2020; Mayner et al., 2018; Oizumi, Albantakis, \& Tononi, 2014; Oizumi, Amari, Yanagawa, Fujii, \& Tsuchiya, 2016; Tegmark, 2016).

IIT-based analyses rest on a solid theoretical foundation in that IIT successfully explains various properties of conscious phenomenology and known neural physiology such as why we can lose consciousness due to brain lesions, general anesthesia, certain types of epilepsy, and deep sleep while our brains remain highly active. IIT suggests that in all these cases, loss of consciousness is caused by disruptions of the structure of integrated information that is otherwise carried by the brain. In other words, IIT assumes a specific type of irreducible causal interactions between neurons that, when perturbed, directly affects conscious experience. In IIT, conscious experience is the integrated information that arises from these neuronal interactions. Thus, any disruption of neural integration of information disrupts consciousness, even if all neurons remain active. The same logic also explains why certain brain lesions, such as in the cerebellum, basal ganglia and even in prefrontal cortex seem to have relatively minor 
impact on consciousness while those in posterior cortical areas are much more severe with regard to consciousness (Boly et al., 2017)(but see: (Odegaard, Knight, \& Lau, 2017)). IIT suggests that this difference is due to the causal structures that are readily available in posterior cortex in the form of lateral connections between cortical columns (A. Haun \& Tononi, 2019; Tononi, Boly, Massimini, \& Koch, 2016).

In addition to this (ad hoc) explanatory power, IIT also makes various testable (often nontrivial, counterintuitive) predictions about what precise neural recordings and causal manipulations can reveal regarding resulting phenomenology. For example, according to IIT the lateral connections among neurons within the retinotopic visual areas (such as V1/V2) will be critical in shaping how we visually perceive space (A. Haun \& Tononi, 2019; Song, Haun, \& Tononi, 2017). IIT predicts that hyperpolarizing already inactive neurons in these areas should completely change space perception. This prediction is based on IIT's notion that lateral connectivity in the retinotopic areas should support topological features of space (such as inclusion, connection, and overlap). Thus, removing even the possibility of causal interactions is sufficient to disrupt these causal properties of the neuronal network underlying the phenomenology of visual space. Importantly, IIT predicts that the warped perception of space following such localized intervention would come about completely independent of other neural mechanisms, such as (top-down) attention. Combined with the novel, massively sampling neurophysiological techniques and sophisticated causal tools such as optogenetics (X. Han \& Boyden, 2007; F. Zhang et al., 2007), neural dust (Seo et al., 2016), non-invasive ultrasound deep brain stimulation (UDBS) (Folloni et al., 2019), ultrasound-based localized drug uncaging (microbubbles) (McDannold, Zhang, \& Vykhodtseva, 2011) and designer receptors exclusively activated by designer drugs (DREADDS) (Roth, 2016), this prediction becomes increasingly empirically testable. Future success rests on this type of strong theoretical guidance on how to link the formalized structure of phenomenology with precise whole brainscale neurophysiology.

Lastly, when we can estimate the structure of information that is set up by neuronal activity together with the corresponding phenomenal structure, we can address the question of the exact relationship between the two. In this context, an exact isomorphism between neuronally construed information and phenomenology might prove too high a bar to be tested empirically. Rather, we propose a step-by-step one-directional test of correspondence (Tsuchiya, Taguchi, \& Saigo, 2016). This test distinguishes IIT's position of assuming identity between the two abstracted structures. For example, we can ask if the structure of phenomenology (e.g., the helical chromatic structure of musical tones and its potential disruption by attentional withdrawal) is preserved in the structure of information derived from neural activity. In the other direction, when we manipulate the brain's connectivity in early visual cortex (Song et al 2017 eNeuro), will the spatial structure of consciousness change as predicted while maintaining the properties of the space? These are feasible tests that approach 
the overarching quest for isomorphism between phenomenal and neuronal information structures. Through multiple iterations of these tests, it is feasible to incrementally approach the ultimate, underlying isomorphism, which promises to conceptually bridge the gap between mind and brain.

In the current context of the division between attention and consciousness, for example, it seems feasible to manipulate attention (Marisa Carrasco, Ling, \& Read, 2004; Matthews, Schröder, Kaunitz, Van Boxtel, \& Tsuchiya, 2018; Prinzmetal, Nwachuku, Bodanski, Blumenfeld, \& Shimizu, 1997) to perturb phenomenology in an attempt to better characterize the phenomenological structure (e.g., does the helical structure of musical chroma morph or even collapse if attention is withdrawn?).

\section{Concluding remarks}

Since Eriksen's seminal work on the impact of unconscious stimuli on heightening one's state of vigilance, much has happened in the science of consciousness and attention. We are now at the edge of a new breakthrough regarding the neuronal dissection of consciousness and attention. Using methodological advances that were unavailable to Eriksen at the time, recent years witnessed a surging amount of convergent evidence that attention and consciousness are dissociable neuronal processes. At the same time, we are witnessing theoretical breakthroughs in our understanding of the formal, relational structure of consciousness. It is exciting to anticipate the insights that will be gained from symbiotically combining these theoretical and technological advances, and yet we realize how much work still needs to be done to truly understand how certain properties of our conscious experiences are supported by neuronal mechanisms.

\section{Acknowledgments}

Authors would like to thank Matthew Davidson for comments on an earlier version of the manuscript. AM is supported by a research grant from the US National Eye Institute (1R01EY027402-03). NT is supported by Australian Research Council (DP180104128 and DP180100396) and National Health and Medical Research Council (APP1183280).

\section{Figure Legends}

Figure 1. $\mathrm{fMRI}$ and EEG evidence for separate neuronal processes underlying attention and consciousness. a) fMRI study showing that, while attention increases neuronal response magnitudes independently of whether a stimulus reached conscious perception, the largest difference in neuronal activity is related to whether a subject was conscious or unconscious of that stimulus (note the difference in units on the $y$-axis). b) EEG response magnitudes to conscious and unconscious stimuli in the presence or absence of attention, showing a similar 
effect as a). c) EEG responses to conscious (magenta) vs. unconscious attentional (cyan) cues. Note that even a cue that is not consciously perceived evokes an elevated (albeit somewhat smaller). EEG response, indicating attentional enhancement of neuronal responses.

Figure 2. Double Dissociations between attention and consciousness demonstrated using E/MEG. a) EEG responses to tactile stimuli that were either consciously perceived or not ( $y$-axis) and at the same time either attended or not (x-axis, red vs. blue). Note that each of these combinations yielded a different EEG response magnitude. b) Spectral profiles of MEG responses to consciously perceived vs. unconscious visual stimuli (left), independent of attentional state and attended vs. unattended stimuli, independent of conscious state (right). Note the difference in frequency and onset for the power maxima of each of the two states.

Figure 3. a) Schematic summary of the effects of attention and conscious state on the magnitude of large-scale sensory brain responses (modified from (Koivisto \& Revonsuo, 2008)). b) summary of the effects of attention and conscious state on the magnitude of large-scale sensory brain responses. Specifically, results are depicted from two single-neuron recording studies that measured the effects of conscious perception (from (David A Leopold, Maier, Wilke, \& Logothetis, 2005), modified) and attentional selection (from (Luck et al., 1997), modified) in the visual cortex of macaque monkeys. Note the similar pattern of enhanced responses co-varying with either phenomenon. Also note that that the magnitude of these enhanced responses varies considerably between cortical areas (i.e., increasing from early sensory cortex towards associative cortex). What is not shown are other changes at the singleneuron level that have been associated with the phenomena, affecting correlated activity, changes in neural noise, intra- and inter-areal coherence and changes in oscillatory activity, some of which cannot be observed when studying single neurons in isolation. Also note that these data sample neurons across entire cortical areas without regard to differences in cell type or neural circuitry (such as cortical layers) that they are embedded in (see (Maier et al., 2007; Sheinberg \& Logothetis, 1997) for a sample of various types of single neuron correlate of consciousness). Thus, the neuronal concomitants of both consciousness and attention are likely more than a simple "boost" in neuronal activity, but rather constitute a complex arrangement of neural mechanisms with distinct regional characteristics.

Figure 4. Promising new technological developments. a) Recent years witnessed a "quantum leap" in the count of simultaneously placed microelectrodes used in animal studies (from (Steinmetz et al., 2018), modified). B) This massive increase in the simultaneously measured activity of single neurons allows for more global (across-the-brain) measures at a submillisecond and sub-millimeter resolution. Given the spatio-temporal complexities associated with the neural concomitants of consciousness and attention (Figure 3 ), this unprecedented 
combination of macroscopic scale and microscopic resolution promises a host of new insights beyond current methodological constraints from (Stringer, Pachitariu, Steinmetz, Reddy, et al., 2019) and (Jun, Steinmetz, Siegle, Denman, Bauza, Barbarits, Lee, Anastassiou, Andrei, Aydin, Barbic, Blanche, Bonin, Couto, Dutta, Gratiy, Gutnisky, Hausser, Karsh, Ledochowitsch, Lopez, Mitelut, Musa, Okun, Pachitariu, Putzeys, Rich, Rossant, Sun, Svoboda, Carandini, Harris, Koch, OKeefe, et al., 2017), modified.

Figure 5. Promising new theoretical directions. A possible research program for an isomorphism between the structure of consciousness and the structure of information derived from the activity and structure of the neuronal activity. First, phenomenological structure needs to be precisely mapped out. As one possible mapping strategy, we can start with characterizing phenomenological relationships between various sounds (e.g., C major chords), as shown here, as well as conscious sensations in other modalities. Attention can be used here as a way to "perturb" phenomenology. These relationships can be quantified and mathematically expressed (e.g., in a multidimensional space through large-scale similarity rating experiments or in other ways using topology or category theory). Here, relationships among variously pitched tones are represented as a helix of musical "chroma" (Shepard, 1982), which captures the essential phenomenological feature of two tones that sound "similar but different". At the neuronal side, connectivity and activity states of the neural networks are measured, and mathematically abstracted to propose physical structures (e.g., informational structure in IIT) that are supposed to give rise to the specific conscious experience. A search for an isomorphism starts with a unidirectional correspondence from one structure to the other (see main text). When both directions converge, we get closer to an isomorphic law that bridges between consciousness and brain activity. Attentional manipulation should preserve this isomorphism. That is, attention cannot change phenomenal structure without changing the information structure set up by neuronal activity, and vice versa. Brain icon is modified from James.mcd.nz, licensed under the Creative Commons Attribution-Share Alike 4.0 International, 3.0 Unported, 2.5 Generic, 2.0 Generic and 1.0 Generic license

(https://commons.wikimedia.org/wiki/File:Brain_Surface_Gyri.SVG). The icon representing the information structure is modified from Takemori39, licensed under the Creative Commons Attribution-Share Alike 3.0 Unported license (https://commons.wikimedia.org/wiki/File:Network_self-organization_stages.png). 


\section{References}

Aquino, T. G., Minxha, J., Dunne, S., Ross, I. B., Mamelak, A. N., Rutishauser, U., \& ODoherty, J. P. (2020). Value-Related Neuronal Responses in the Human Amygdala during Observational Learning. J Neurosci, 40(24), 4761-4772. doi:10.1523/JNEUROSCI.289719.2020

Arcizet, F., \& Krauzlis, R. J. (2018). Covert spatial selection in primate basal ganglia. PLoS Biol, 16(10), e2005930. doi:10.1371/journal.pbio.2005930

Aru, J., Bachmann, T., Singer, W., \& Melloni, L. (2012). Distilling the neural correlates of consciousness. Neurosci Biobehav Rev, 36(2), 737-746.

doi:10.1016/j.neubiorev.2011.12.003

Bachmann, T., \& Hudetz, A. G. (2014). It is time to combine the two main traditions in the research on the neural correlates of consciousness: $C=L \times D$. Front Psychol, 5, 940. doi:10.3389/fpsyg.2014.00940

Barrett, A. B., \& Seth, A. K. (2011). Practical measures of integrated information for time-series data. PLoS Comput Biol, 7(1), e1001052. doi:10.1371/journal.pcbi.1001052

Blake, R., \& Logothetis, N. (2002). Visual competition. Nat Rev Neurosci, 3(1), 13-21. doi:10.1038/nrn701

Block, N. (2005). Two neural correlates of consciousness. Trends Cogn Sci, 9(2), 46-52. doi:10.1016/j.tics.2004.12.006

Block, N., Carmel, D., Fleming, S. M., Kentridge, R. W., Koch, C., Lamme, V. A., . . Rosenthal, D. (2014). Consciousness science: real progress and lingering misconceptions. Trends Cogn Sci, 18(11), 556-557. doi:10.1016/j.tics.2014.09.004

Boehler, C. N., Schoenfeld, M. A., Heinze, H. J., \& Hopf, J. M. (2008). Rapid recurrent processing gates awareness in primary visual cortex. Proc Natl Acad Sci U S A, 105(25), 8742-8747. doi:10.1073/pnas.0801999105

Bogadhi, A. R., Bollimunta, A., Leopold, D. A., \& Krauzlis, R. J. (2018). Brain regions modulated during covert visual attention in the macaque. Sci Rep, 8(1), 15237. doi:10.1038/s41598018-33567-9

Bollimunta, A., Bogadhi, A. R., \& Krauzlis, R. J. (2018). Comparing frontal eye field and superior colliculus contributions to covert spatial attention. Nat Commun, 9(1), 3553. doi:10.1038/s41467-018-06042-2

Boly, M., Massimini, M., Tsuchiya, N., Postle, B. R., Koch, C., \& Tononi, G. (2017). Are the Neural Correlates of Consciousness in the Front or in the Back of the Cerebral Cortex? Clinical and Neuroimaging Evidence. J Neurosci, 37(40), 9603-9613. doi:10.1523/JNEUROSCI.3218-16.2017

Boly, M., Seth, A. K., Wilke, M., Ingmundson, P., Baars, B., Laureys, S., . . Tsuchiya, N. (2013). Consciousness in humans and non-human animals: recent advances and future directions. Front Psychol, 4, 625. doi:10.3389/fpsyg.2013.00625

Bosman, C. A., Schoffelen, J. M., Brunet, N., Oostenveld, R., Bastos, A. M., Womelsdorf, T., ... Fries, P. (2012). Attentional stimulus selection through selective synchronization between monkey visual areas. Neuron, 75(5), 875-888. doi:10.1016/j.neuron.2012.06.037 
Brascamp, J., Sterzer, P., Blake, R., \& Knapen, T. (2018). Multistable Perception and the Role of the Frontoparietal Cortex in Perceptual Inference. Annu Rev Psychol, 69, 77-103. doi:10.1146/annurev-psych-010417-085944

Brascamp, J. W., van Boxtel, J. J., Knapen, T. H., \& Blake, R. (2010). A dissociation of attention and awareness in phase-sensitive but not phase-insensitive visual channels. J Cogn Neurosci, 22(10), 2326-2344. doi:10.1162/jocn.2009.21397

Brown, R. J., \& Norcia, A. M. (1997). A method for investigating binocular rivalry in real-time with the steady-state VEP. Vision research, 37(17), 2401-2408.

Carrasco, M. (2011). Visual attention: the past 25 years. Vision Res, 51(13), 1484-1525. doi:10.1016/j.visres.2011.04.012

Carrasco, M., Ling, S., \& Read, S. (2004). Attention alters appearance. Nature neuroscience, 7(3), 308-313.

Cha, O., \& Blake, R. (2019). Evidence for neural rhythms embedded within binocular rivalry. Proc Natl Acad Sci U S A, 116(30), 14811-14812. doi:10.1073/pnas.1905174116

Chica, A. B., Bayle, D. J., Botta, F., Bartolomeo, P., \& Paz-Alonso, P. M. (2016). Interactions between phasic alerting and consciousness in the fronto-striatal network. Sci Rep, 6, 31868. doi:10.1038/srep31868

Chica, A. B., Lasaponara, S., Lupianez, J., Doricchi, F., \& Bartolomeo, P. (2010). Exogenous attention can capture perceptual consciousness: ERP and behavioural evidence. Neuroimage, 51(3), 1205-1212. doi:10.1016/j.neuroimage.2010.03.002

Cohen, M. A., Botch, T. L., \& Robertson, C. E. (2020). The limits of color awareness during active, real-world vision. Proc Natl Acad Sci U S A, 117(24), 13821-13827. doi:10.1073/pnas.1922294117

Cohen, M. A., Cavanagh, P., Chun, M. M., \& Nakayama, K. (2012). The attentional requirements of consciousness. Trends Cogn Sci, 16(8), 411-417. doi:10.1016/j.tics.2012.06.013

Cohen, M. A., Dennett, D. C., \& Kanwisher, N. (2016). What is the bandwidth of perceptual experience? Trends in cognitive sciences, 20(5), 324-335.

Cohen, M. A., Ortego, K., Kyroudis, A., \& Pitts, M. (2020). Distinguishing the Neural Correlates of Perceptual Awareness and Postperceptual Processing. J Neurosci, 40(25), 4925-4935. doi:10.1523/JNEUROSCI.0120-20.2020

Corballis, M. C. (1995). Visual integration in the split brain. Neuropsychologia, 33(8), 937-959. doi:10.1016/0028-3932(95)00032-x

D'Andrea, A., Chella, F., Marshall, T. R., Pizzella, V., Romani, G. L., Jensen, O., \& Marzetti, L. (2019). Alpha and alpha-beta phase synchronization mediate the recruitment of the visuospatial attention network through the Superior Longitudinal Fasciculus. Neuroimage, 188, 722-732. doi:10.1016/j.neuroimage.2018.12.056

Davidson, M. J., Alais, D., vanBoxtel, J. J., \& Tsuchiya, N. (2018). Attention periodically samples competing stimuli during binocular rivalry. Elife, 7, e40868.

Davidson, M. J., Graafsma, I. L., Tsuchiya, N., \& van Boxtel, J. (2020). A multiple-response frequency-tagging paradigm measures graded changes in consciousness during perceptual filling-in. Neurosci Conscious, 2020(1), niaa002. doi:10.1093/nc/niaa002

Davidson, M. J., Mithen, W., Hogendoorn, H., vanBoxtel, J. J. A., \& Tsuchiya, N. (2020). A neural representation of invisibility: when stimulus-specific neural activity negatively correlates 
with conscious experience. bioRxiv, 2020.2004.2020.051334.

doi:10.1101/2020.04.20.051334

DeGraaf, T. A., Hsieh, P.-J., \& Sack, A. T. (2012). The 'correlates' in neural correlates of consciousness. Neuroscience \& Biobehavioral Reviews, 36(1), 191-197.

Dehaene, S., Changeux, J. P., Naccache, L., Sackur, J., \& Sergent, C. (2006). Conscious, preconscious, and subliminal processing: a testable taxonomy. Trends Cogn Sci, 10(5), 204-211. doi:10.1016/j.tics.2006.03.007

DeWeerd, P., Smith, E., \& Greenberg, P. (2006). Effects of selective attention on perceptual filling-in. J Cogn Neurosci, 18(3), 335-347. doi:10.1162/089892906775990561

Donoghue, J., Bastos, A. M., Yanar, J., Kornblith, S., Mahnke, M., Brown, E. N., \& Miller, E. K. (2019). Neural signatures of loss of consciousness and its recovery by thalamic stimulation. bioRxiv, 806687.

Dougherty, K., Schmid, M. C., \& Maier, A. (2018). Binocular Response Modulation in the Lateral Geniculate Nucleus. Journal of Comparative Neurology. doi:10.1002/cne.24417

Eriksen, C. W. (1956). An experimental analysis of subception. The American journal of psychology, 69(4), 625-634.

Eriksen, C. W. (1960). Discrimination and learning without awareness: a methodological survey and evaluation. Psychological review, 67(5), 279.

Faivre, N., \& Kouider, S. (2011). Multi-feature objects elicit nonconscious priming despite crowding. J Vis, 11(3). doi:10.1167/11.3.2

Fiebelkorn, I. C., \& Kastner, S. (2019). A Rhythmic Theory of Attention. Trends Cogn Sci, 23(2), 87-101. doi:10.1016/j.tics.2018.11.009

Fiebelkorn, I. C., \& Kastner, S. (2020). Functional Specialization in the Attention Network. Annu Rev Psychol, 71, 221-249. doi:10.1146/annurev-psych-010418-103429

Folloni, D., Verhagen, L., Mars, R. B., Fouragnan, E., Constans, C., Aubry, J. F., . . Sallet, J. (2019). Manipulation of Subcortical and Deep Cortical Activity in the Primate Brain Using Transcranial Focused Ultrasound Stimulation. Neuron, 101(6), 1109-1116 e1105. doi:10.1016/j.neuron.2019.01.019

Forschack, N., Nierhaus, T., Muller, M. M., \& Villringer, A. (2017). Alpha-Band Brain Oscillations Shape the Processing of Perceptible as well as Imperceptible Somatosensory Stimuli during Selective Attention. J Neurosci, 37(29), 6983-6994. doi:10.1523/JNEUROSCI.258216.2017

Frassle, S., Sommer, J., Jansen, A., Naber, M., \& Einhauser, W. (2014). Binocular rivalry: frontal activity relates to introspection and action but not to perception. $J$ Neurosci, 34(5), 1738-1747. doi:10.1523/JNEUROSCI.4403-13.2014

Frith, C., Perry, R., \& Lumer, E. (1999). The neural correlates of conscious experience: An experimental framework. Trends in cognitive sciences, 3(3), 105-114.

Gazzaniga, M. S. (2014). The split-brain: rooting consciousness in biology. Proc Natl Acad Sci U S A, 111(51), 18093-18094. doi:10.1073/pnas.1417892111

Geng, H., Song, Q., Li, Y., Xu, S., \& Zhu, Y. (2007). Attentional modulation of motion-induced blindness. Chinese Science Bulletin, 52(8), 1063-1070.

Gould, I. C., Rushworth, M. F., \& Nobre, A. C. (2011). Indexing the graded allocation of visuospatial attention using anticipatory alpha oscillations. J Neurophysiol, 105(3), 13181326. doi:10.1152/jn.00653.2010 
Gärdenfors, P. (2000). Conceptual spaces: The geometry of thought. A Bradford book. MIT Press, 3, 16.

Halassa, M. M., \& Kastner, S. (2017). Thalamic functions in distributed cognitive control. Nat Neurosci, 20(12), 1669-1679. doi:10.1038/s41593-017-0020-1

Han, S. W., \& Marois, R. (2014). Functional fractionation of the stimulus-driven attention network. J Neurosci, 34(20), 6958-6969. doi:10.1523/JNEUROSCI.4975-13.2014

Han, X., \& Boyden, E. S. (2007). Multiple-color optical activation, silencing, and desynchronization of neural activity, with single-spike temporal resolution. PLoS One, 2(3), e299. doi:10.1371/journal.pone.0000299

Haun, A., \& Tononi, G. (2019). Why does space feel the way it does? Towards a principled account of spatial experience. Entropy, 21(12), 1160.

Haun, A. M., Oizumi, M., Kovach, C. K., Kawasaki, H., Oya, H., Howard, M. A., . . Tsuchiya, N. (2017). Conscious perception as integrated information patterns in human electrocorticography. Eneuro, 4(5).

Hayden, B. Y., Smith, D. V., \& Platt, M. L. (2009). Electrophysiological correlates of default-mode processing in macaque posterior cingulate cortex. Proc Natl Acad Sci U S A, 106(14), 5948-5953. doi:10.1073/pnas.0812035106

Helfrich, R. F., Fiebelkorn, I. C., Szczepanski, S. M., Lin, J. J., Parvizi, J., Knight, R. T., \& Kastner, S. (2018). Neural Mechanisms of Sustained Attention Are Rhythmic. Neuron, 99(4), 854865 e855. doi:10.1016/j.neuron.2018.07.032

Hodgetts, C. J., \& Hahn, U. (2012). Similarity-based asymmetries in perceptual matching. Acta Psychol (Amst), 139(2), 291-299. doi:10.1016/j.actpsy.2011.12.003

Hohwy, J. (2009). The neural correlates of consciousness: new experimental approaches needed? Conscious Cogn, 18(2), 428-438. doi:10.1016/j.concog.2009.02.006

Horschig, J. M., Oosterheert, W., Oostenveld, R., \& Jensen, O. (2015). Modulation of Posterior Alpha Activity by Spatial Attention Allows for Controlling A Continuous Brain-Computer Interface. Brain Topogr, 28(6), 852-864. doi:10.1007/s10548-014-0401-7

Huang, L., Mo, L., \& Li, Y. (2012). Measuring the interrelations among multiple paradigms of visual attention: an individual differences approach. J Exp Psychol Hum Percept Perform, 38(2), 414-428. doi:10.1037/a0026314

Isik, L., Singer, J., Madsen, J. R., Kanwisher, N., \& Kreiman, G. (2018). What is changing when: Decoding visual information in movies from human intracranial recordings. Neuroimage, 180(Pt A), 147-159. doi:10.1016/j.neuroimage.2017.08.027

James, W. (1890). The principles of psychology. New York, : H. Holt and company.

Jensen, O., Gips, B., Bergmann, T. O., \& Bonnefond, M. (2014). Temporal coding organized by coupled alpha and gamma oscillations prioritize visual processing. Trends Neurosci, 37(7), 357-369. doi:10.1016/j.tins.2014.04.001

Jia, X., Siegle, J. H., Bennett, C., Gale, S. D., Denman, D. J., Koch, C., \& Olsen, S. R. (2019). Highdensity extracellular probes reveal dendritic backpropagation and facilitate neuron classification. J Neurophysiol, 121(5), 1831-1847. doi:10.1152/jn.00680.2018

Jun, J. J., Steinmetz, N. A., Siegle, J. H., Denman, D. J., Bauza, M., Barbarits, B., . . Harris, T. D. (2017). Fully integrated silicon probes for high-density recording of neural activity. Nature, 551(7679), 232-236. doi:10.1038/nature24636 
Jun, J. J., Steinmetz, N. A., Siegle, J. H., Denman, D. J., Bauza, M., Barbarits, B., . . Harris, T. D. (2017). Fully integrated silicon probes for high-density recording of neural activity. Nature, 551(7679), 232-236. doi:10.1038/nature24636

Kaas, J. H. (2012a). Evolution of columns, modules, and domains in the neocortex of primates. Proc Natl Acad Sci U S A, 109 Suppl 1, 10655-10660. doi:10.1073/pnas.1201892109

Kaas, J. H. (2012b). The evolution of neocortex in primates. Prog Brain Res, 195, 91-102. doi:10.1016/B978-0-444-53860-4.00005-2

Kaas, J. H. (2013). The Evolution of Brains from Early Mammals to Humans. Wiley Interdiscip Rev Cogn Sci, 4(1), 33-45. doi:10.1002/wcs.1206

Kentridge, R. W., Heywood, C. A., \& Weiskrantz, L. (1999). Attention without awareness in blindsight. Proc Biol Sci, 266(1430), 1805-1811. doi:10.1098/rspb.1999.0850

Kentridge, R. W., Heywood, C. A., \& Weiskrantz, L. (2004). Spatial attention speeds discrimination without awareness in blindsight. Neuropsychologia, 42(6), 831-835. doi:10.1016/j.neuropsychologia.2003.11.001

Kentridge, R. W., Nijboer, T. C., \& Heywood, C. A. (2008). Attended but unseen: visual attention is not sufficient for visual awareness. Neuropsychologia, 46(3), 864-869. doi:10.1016/j.neuropsychologia.2007.11.036

Kiefer, M., \& Brendel, D. (2006). Attentional modulation of unconscious "automatic" processes: evidence from event-related potentials in a masked priming paradigm. J Cogn Neurosci, 18(2), 184-198. doi:10.1162/089892906775783688

Kiefer, M., \& Martens, U. (2010). Attentional sensitization of unconscious cognition: task sets modulate subsequent masked semantic priming. J Exp Psychol Gen, 139(3), 464-489. doi:10.1037/a0019561

Kienitz, R., Schmiedt, J. T., Shapcott, K. A., Kouroupaki, K., Saunders, R. C., \& Schmid, M. C. (2018). Theta Rhythmic Neuronal Activity and Reaction Times Arising from Cortical Receptive Field Interactions during Distributed Attention. Curr Biol, 28(15), 2377-2387 e2375. doi:10.1016/j.cub.2018.05.086

Koch, C., Massimini, M., Boly, M., \& Tononi, G. (2016). Neural correlates of consciousness: progress and problems. Nat Rev Neurosci, 17(5), 307-321. doi:10.1038/nrn.2016.22

Koch, C., \& Tsuchiya, N. (2007). Attention and consciousness: two distinct brain processes. Trends Cogn Sci, 11(1), 16-22. doi:10.1016/j.tics.2006.10.012

Koch, C., \& Tsuchiya, N. (2012). Attention and consciousness: related yet different. Trends Cogn Sci, 16(2), 103-105. doi:10.1016/j.tics.2011.11.012

Koivisto, M., \& Revonsuo, A. (2007). Electrophysiological correlates of visual consciousness and selective attention. Neuroreport, 18(8), 753-756. doi:10.1097/WNR.0b013e3280c143c8

Koivisto, M., \& Revonsuo, A. (2008). The role of selective attention in visual awareness of stimulus features: electrophysiological studies. Cogn Affect Behav Neurosci, 8(2), 195210. doi:10.3758/cabn.8.2.195

Koivisto, M., Revonsuo, A., \& Lehtonen, M. (2006). Independence of visual awareness from the scope of attention: an electrophysiological study. Cereb Cortex, 16(3), 415-424. doi:10.1093/cercor/bhi121

Kouider, S., Barbot, A., Madsen, K. H., Lehericy, S., \& Summerfield, C. (2016). Task relevance differentially shapes ventral visual stream sensitivity to visible and invisible faces. Neurosci Conscious, 2016(1), niw021. doi:10.1093/nc/niw021 
Krauzlis, R. J., Bogadhi, A. R., Herman, J. P., \& Bollimunta, A. (2018). Selective attention without a neocortex. Cortex, 102, 161-175. doi:10.1016/j.cortex.2017.08.026

Krauzlis, R. J., Bollimunta, A., Arcizet, F., \& Wang, L. (2014). Attention as an effect not a cause. Trends Cogn Sci, 18(9), 457-464. doi:10.1016/j.tics.2014.05.008

Krauzlis, R. J., Lovejoy, L. P., \& Zenon, A. (2013). Superior colliculus and visual spatial attention. Annu Rev Neurosci, 36, 165-182. doi:10.1146/annurev-neuro-062012-170249

Kreiman, G., Koch, C., \& Fried, I. (2000). Imagery neurons in the human brain. Nature, 408(6810), 357-361. doi:10.1038/35042575

Lamme, V. A. (2003). Why visual attention and awareness are different. Trends Cogn Sci, 7(1), 12-18. doi:10.1016/s1364-6613(02)00013-x

Lamme, V. A. (2004). Separate neural definitions of visual consciousness and visual attention; a case for phenomenal awareness. Neural Netw, 17(5-6), 861-872. doi:10.1016/j.neunet.2004.02.005

Landau, A. N., \& Fries, P. (2012). Attention samples stimuli rhythmically. Curr Biol, 22(11), $1000-$ 1004. doi:10.1016/j.cub.2012.03.054

Lansing, R. W. (1964). Electroencephalographic Correlates of Binocular Rivalry in Man. Science, 146(3649), 1325-1327. doi:10.1126/science.146.3649.1325

Lazarus, R. S., \& McCleary, R. A. (1951). Autonomic discrimination without awareness: A study of subception. Psychological review, 58(2), 113.

Leopold, D. A., \& Logothetis, N. K. (1999). Multistable phenomena: changing views in perception. Trends Cogn Sci, 3(7), 254-264. doi:10.1016/s1364-6613(99)01332-7

Leopold, D. A., Maier, A., \& Logothetis, N. K. (2003). Measuring subjective visual perception in the nonhuman primate. Journal of Consciousness Studies, 10(9-10), 115-130.

Leopold, D. A., Maier, A., Wilke, M., \& Logothetis, N. K. (2005). Binocular Rivalry and the Illusion of Monocular Vision. Binocular rivalry, 231.

Leung, A., Cohen, D., Van Swinderen, B., \& Tsuchiya, N. (2020). Integrated information structure collapses with anesthetic loss of conscious arousal in Drosophila melanogaster. BioRxiv.

Lohmann, G., Von Cramon, D. Y., \& Steinmetz, H. (1999). Sulcal variability of twins. Cerebral Cortex, 9(7), 754-763.

Lou, L. (1999). Selective peripheral fading: evidence for inhibitory sensory effect of attention. Perception, 28(4), 519-526. doi:10.1068/p2816

Lou, L. (2001). Effects of voluntary attention on structured afterimages. Perception, 30(12), 1439-1448. doi:10.1068/p3127

Luck, S. J., Chelazzi, L., Hillyard, S. A., \& Desimone, R. (1997). Neural mechanisms of spatial selective attention in areas V1, V2, and V4 of macaque visual cortex. J Neurophysiol, 77(1), 24-42. doi:10.1152/jn.1997.77.1.24

Lumer, E. D., Friston, K. J., \& Rees, G. (1998). Neural correlates of perceptual rivalry in the human brain. Science, 280(5371), 1930-1934. doi:10.1126/science.280.5371.1930

Lundqvist, M. K., Bastos, A. M., \& Miller, E. K. (2020). Preservation and changes in oscillatory dynamics across the cortex. bioRxiv.

Luo, T. Z., \& Maunsell, J. H. R. (2019). Attention can be subdivided into neurobiological components corresponding to distinct behavioral effects. Proc Natl Acad Sci U S A. doi:10.1073/pnas.1902286116 
Maier, A., Logothetis, N. K., \& Leopold, D. A. (2007). Context-dependent perceptual modulation of single neurons in primate visual cortex. Proceedings of the National Academy of Sciences of the United States of America, 104(13), 5620-5625. doi:10.1073/pnas.0608489104

Maier, A., Panagiotaropoulos, T. I., Tsuchiya, N., \& Keliris, G. A. (2012). Introduction to research topic - binocular rivalry: A gateway to studying consciousness. Frontiers in Human Neuroscience(SEPTEMBER), 1-3. doi:10.3389/fnhum.2012.00263

Martens, U., Ansorge, U., \& Kiefer, M. (2011). Controlling the unconscious: attentional task sets modulate subliminal semantic and visuomotor processes differentially. Psychol Sci, 22(2), 282-291. doi:10.1177/0956797610397056

Mashour, G. A., Roelfsema, P., Changeux, J. P., \& Dehaene, S. (2020). Conscious Processing and the Global Neuronal Workspace Hypothesis. Neuron, 105(5), 776-798. doi:10.1016/j.neuron.2020.01.026

Matthews, J., Schröder, P., Kaunitz, L., Van Boxtel, J. J., \& Tsuchiya, N. (2018). Conscious access in the near absence of attention: critical extensions on the dual-task paradigm. Philosophical Transactions of the Royal Society B: Biological Sciences, 373(1755), 20170352.

Maunsell, J. H. R. (2015). Neuronal Mechanisms of Visual Attention. Annu Rev Vis Sci, 1, 373391. doi:10.1146/annurev-vision-082114-035431

Mayner, W. G. P., Marshall, W., Albantakis, L., Findlay, G., Marchman, R., \& Tononi, G. (2018). PyPhi: A toolbox for integrated information theory. PLoS Comput Biol, 14(7), e1006343. doi:10.1371/journal.pcbi.1006343

McDannold, N., Zhang, Y., \& Vykhodtseva, N. (2011). Blood-brain barrier disruption and vascular damage induced by ultrasound bursts combined with microbubbles can be influenced by choice of anesthesia protocol. Ultrasound Med Biol, 37(8), 1259-1270. doi:10.1016/j.ultrasmedbio.2011.04.019

Merten, K., \& Nieder, A. (2012). Active encoding of decisions about stimulus absence in primate prefrontal cortex neurons. Proceedings of the National Academy of Sciences, 109(16), 6289-6294.

Michel, M., Beck, D., Block, N., Blumenfeld, H., Brown, R., Carmel, D., . . Yoshida, M. (2019). Opportunities and challenges for a maturing science of consciousness. Nat Hum Behav, 3(2), 104-107. doi:10.1038/s41562-019-0531-8

Mitchell, J. F., Sundberg, K. A., \& Reynolds, J. H. (2009). Spatial attention decorrelates intrinsic activity fluctuations in macaque area V4. Neuron, 63(6), 879-888. doi:10.1016/j.neuron.2009.09.013

Montemayor, C., \& Haladjian, H. H. (2019). Recurrent processing theory versus global neuronal workspace theory: a comment on 'The relationship between attention and consciousness: an expanded taxonomy and implications for 'no-report' paradigms' by Pitts et al. Philos Trans R Soc Lond B Biol Sci, 374(1770), 20180517. doi:10.1098/rstb.2018.0517

Morgan, S. T., Hansen, J. C., \& Hillyard, S. A. (1996). Selective attention to stimulus location modulates the steady-state visual evoked potential. Proc Natl Acad Sci U S A, 93(10), 4770-4774. doi:10.1073/pnas.93.10.4770 
Muller, M. M., Andersen, S., Trujillo, N. J., Valdes-Sosa, P., Malinowski, P., \& Hillyard, S. A. (2006). Feature-selective attention enhances color signals in early visual areas of the human brain. Proc Natl Acad Sci U S A, 103(38), 14250-14254. doi:10.1073/pnas.0606668103

Musk, E. (2019). An integrated brain-machine interface platform with thousands of channels. Journal of medical Internet research, 21(10), e16194.

Naccache, L., Blandin, E., \& Dehaene, S. (2002). Unconscious masked priming depends on temporal attention. Psychol Sci, 13(5), 416-424. doi:10.1111/1467-9280.00474

Nani, A., Manuello, J., Mancuso, L., Liloia, D., Costa, T., \& Cauda, F. (2019). The Neural Correlates of Consciousness and Attention: Two Sister Processes of the Brain. Front Neurosci, 13, 1169. doi:10.3389/fnins.2019.01169

Norcia, A. M., Appelbaum, L. G., Ales, J. M., Cottereau, B. R., \& Rossion, B. (2015). The steadystate visual evoked potential in vision research: A review. J Vis, 15(6), 4. doi:10.1167/15.6.4

Noy, N., Bickel, S., Zion-Golumbic, E., Harel, M., Golan, T., Davidesco, I., . . Malach, R. (2015). Ignition's glow: Ultra-fast spread of global cortical activity accompanying local "ignitions" in visual cortex during conscious visual perception. Conscious Cogn, 35, 206224. doi:10.1016/j.concog.2015.03.006

O'Regan, J. K., \& Noe, A. (2001). A sensorimotor account of vision and visual consciousness. Behav Brain Sci, 24(5), 939-973; discussion 973-1031. doi:10.1017/s0140525x01000115

Odegaard, B., Knight, R. T., \& Lau, H. (2017). Should a Few Null Findings Falsify Prefrontal Theories of Conscious Perception? J Neurosci, 37(40), 9593-9602. doi:10.1523/JNEUROSCI.3217-16.2017

Oizumi, M., Albantakis, L., \& Tononi, G. (2014). From the phenomenology to the mechanisms of consciousness: Integrated Information Theory 3.0. PLoS Comput Biol, 10(5), e1003588. doi:10.1371/journal.pcbi.1003588

Oizumi, M., Amari, S., Yanagawa, T., Fujii, N., \& Tsuchiya, N. (2016). Measuring Integrated Information from the Decoding Perspective. PLoS Comput Biol, 12(1), e1004654. doi:10.1371/journal.pcbi.1004654

Otazu, G. H., Tai, L. H., Yang, Y., \& Zador, A. M. (2009). Engaging in an auditory task suppresses responses in auditory cortex. Nat Neurosci, 12(5), 646-654. doi:10.1038/nn.2306

Pachitariu, M., Steinmetz, N. A., Kadir, S. N., Carandini, M., \& Harris, K. D. (2016). Fast and accurate spike sorting of high-channel count probes with KiloSort. Paper presented at the Advances in neural information processing systems.

Palmer, S. E. (1999). Color, consciousness, and the isomorphism constraint. Behav Brain Sci, 22(6), 923-943; discussion 944-989. doi:10.1017/s0140525x99002216

Parker, A. J., \& Newsome, W. T. (1998). Sense and the single neuron: probing the physiology of perception. Annu Rev Neurosci, 21, 227-277. doi:10.1146/annurev.neuro.21.1.227

Pinto, Y., de Haan, E. H. F., \& Lamme, V. A. F. (2017). The Split-Brain Phenomenon Revisited: A Single Conscious Agent with Split Perception. Trends Cogn Sci, 21(11), 835-851. doi:10.1016/j.tics.2017.09.003

Pinto, Y., Lamme, V. A. F., \& de Haan, E. H. F. (2017). Cross-cueing cannot explain unified control in split-brain patients. Brain, 140(11), e68. doi:10.1093/brain/awx235 
Pinto, Y., Neville, D. A., Otten, M., Corballis, P. M., Lamme, V. A. F., de Haan, E. H. F., . . Fabri, M. (2017). Split brain: divided perception but undivided consciousness. Brain, 140(5), 1231-1237. doi:10.1093/brain/aww358

Pitts, M. A., Padwal, J., Fennelly, D., Martinez, A., \& Hillyard, S. A. (2014). Gamma band activity and the $\mathrm{P} 3$ reflect post-perceptual processes, not visual awareness. Neuroimage, 101, 337-350. doi:10.1016/j.neuroimage.2014.07.024

Polk, T. A., Behensky, C., Gonzalez, R., \& Smith, E. E. (2002). Rating the similarity of simple perceptual stimuli: asymmetries induced by manipulating exposure frequency. Cognition, 82(3), B75-88. doi:10.1016/s0010-0277(01)00151-2

Pooresmaeili, A., Poort, J., Thiele, A., \& Roelfsema, P. R. (2010). Separable codes for attention and luminance contrast in the primary visual cortex. J Neurosci, 30(38), 12701-12711. doi:10.1523/JNEUROSCI.1388-10.2010

Pothos, E. M., Busemeyer, J. R., \& Trueblood, J. S. (2013). A quantum geometric model of similarity. Psychol Rev, 120(3), 679-696. doi:10.1037/a0033142

Prentner, R. (2019). Consciousness and topologically structured phenomenal spaces. Consciousness and cognition, 70, 25-38.

Prinzmetal, W., Nwachuku, I. I., Bodanski, L., Blumenfeld, L., \& Shimizu, N. (1997). The Phenomenology of Attention. Conscious Cogn, 6(2/3), 372-412.

Pryluk, R., Kfir, Y., Gelbard-Sagiv, H., Fried, I., \& Paz, R. (2019). A Tradeoff in the Neural Code across Regions and Species. Cell, 176(3), 597-609 e518. doi:10.1016/j.cell.2018.12.032

Raichle, M. E. (2015). The brain's default mode network. Annu Rev Neurosci, 38, 433-447. doi:10.1146/annurev-neuro-071013-014030

Redinbaugh, M. J., Phillips, J. M., Kambi, N. A., Mohanta, S., Andryk, S., Dooley, G. L., . . . Saalmann, Y. B. (2020). Thalamus modulates consciousness via layer-specific control of cortex. Neuron.

Rees, G., Kreiman, G., \& Koch, C. (2002). Neural correlates of consciousness in humans. Nat Rev Neurosci, 3(4), 261-270. doi:10.1038/nrn783

Robbins, T. W., Granon, S., Muir, J. L., Durantou, F., Harrison, A., \& Everitt, B. J. (1998). Neural systems underlying arousal and attention. Implications for drug abuse. Ann N Y Acad Sci, 846, 222-237.

Roelfsema, P. R., \& Treue, S. (2014). Basic neuroscience research with nonhuman primates: a small but indispensable component of biomedical research. Neuron, 82(6), 1200-1204. doi:10.1016/j.neuron.2014.06.003

Roth, B. L. (2016). DREADDs for Neuroscientists. Neuron, 89(4), 683-694. doi:10.1016/j.neuron.2016.01.040

Ruff, D. A., \& Cohen, M. R. (2014). Attention can either increase or decrease spike count correlations in visual cortex. Nat Neurosci, 17(11), 1591-1597. doi:10.1038/nn.3835

Rutishauser, U., Tudusciuc, O., Wang, S., Mamelak, A. N., Ross, I. B., \& Adolphs, R. (2013). Single-neuron correlates of atypical face processing in autism. Neuron, 80(4), 887-899. doi:10.1016/j.neuron.2013.08.029

Rutishauser, U., Ye, S., Koroma, M., Tudusciuc, O., Ross, I. B., Chung, J. M., \& Mamelak, A. N. (2015). Representation of retrieval confidence by single neurons in the human medial temporal lobe. Nat Neurosci, 18(7), 1041-1050. doi:10.1038/nn.4041 
Saalmann, Y. B., \& Kastner, S. (2011). Cognitive and perceptual functions of the visual thalamus. Neuron, 71(2), 209-223. doi:10.1016/j.neuron.2011.06.027

Saalmann, Y. B., Pinsk, M. A., Wang, L., Li, X., \& Kastner, S. (2012). The pulvinar regulates information transmission between cortical areas based on attention demands. Science, 337(6095), 753-756. doi:10.1126/science.1223082

Sanchez-Lopez, J., Savazzi, S., Pedersini, C. A., Cardobi, N., \& Marzi, C. A. (2019). Neural Correlates of Visuospatial Attention to Unseen Stimuli in Hemianopic Patients. A SteadyState Visual Evoked Potential Study. Front Psychol, 10, 198. doi:10.3389/fpsyg.2019.00198

Schieting, S., \& Spillmann, L. (1987). Flicker adaptation in the peripheral retina. Vision Res, 27(2), 277-284. doi:10.1016/0042-6989(87)90190-8

Schmid, M. C., \& Maier, A. (2015). To see or not to see - thalamo-cortical networks during blindsight and perceptual suppression. Progress in Neurobiology, 126, 36-48. doi:10.1016/j.pneuroblo.2015.01.001

Scholvinck, M. L., \& Rees, G. (2009). Attentional influences on the dynamics of motion-induced blindness. J Vis, 9(1), 38 31-39. doi:10.1167/9.1.38

Schurger, A., Cowey, A., Cohen, J. D., Treisman, A., \& Tallon-Baudry, C. (2008). Distinct and independent correlates of attention and awareness in a hemianopic patient. Neuropsychologia, 46(8), 2189-2197. doi:10.1016/j.neuropsychologia.2008.02.020

Seo, D., Neely, R. M., Shen, K., Singhal, U., Alon, E., Rabaey, J. M., . . Maharbiz, M. M. (2016). Wireless Recording in the Peripheral Nervous System with Ultrasonic Neural Dust. Neuron, 91(3), 529-539. doi:10.1016/j.neuron.2016.06.034

Sewards, T. V., \& Sewards, M. A. (2001). On the correlation between synchronized oscillatory activities and consciousness. Conscious Cogn, 10(4), 485-495. doi:10.1006/ccog.2001.0520

Shapcott, K. A., Schmiedt, J. T., Kouroupaki, K., Kienitz, R., Lazar, A., Singer, W., \& Schmid, M. C. (2020). Reward-Related Suppression of Neural Activity in Macaque Visual Area V4. Cereb Cortex. doi:10.1093/cercor/bhaa079

Sheinberg, D. L., \& Logothetis, N. K. (1997). The role of temporal cortical areas in perceptual organization. Proceedings of the National Academy of Sciences, 94(7), 3408-3413.

Shepard, R. N. (1982). Geometrical approximations to the structure of musical pitch. Psychological review, 89(4), 305.

Smout, C. A., \& Mattingley, J. B. (2018). Spatial Attention Enhances the Neural Representation of Invisible Signals Embedded in Noise. J Cogn Neurosci, 30(8), 1119-1129. doi:10.1162/jocn_a_01283

Song, C., Haun, A. M., \& Tononi, G. (2017). Plasticity in the structure of visual space. Eneuro, 4(3).

Spaak, E., Bonnefond, M., Maier, A., Leopold, D. A., \& Jensen, O. (2012). Layer-specific entrainment of gamma-band neural activity by the alpha rhythm in monkey visual cortex. Current Biology, 22(24), 2313-2318. doi:10.1016/j.cub.2012.10.020

Steinmetz, N. A., Koch, C., Harris, K. D., \& Carandini, M. (2018). Challenges and opportunities for large-scale electrophysiology with Neuropixels probes. Curr Opin Neurobiol, 50, 92-100. doi:10.1016/j.conb.2018.01.009 
Steinmetz, N. A., Zatka-Haas, P., Carandini, M., \& Harris, K. D. (2019). Distributed coding of choice, action and engagement across the mouse brain. Nature, 576(7786), 266-273. doi:10.1038/s41586-019-1787-x

Stringer, C., Pachitariu, M., Steinmetz, N., Carandini, M., \& Harris, K. D. (2019). Highdimensional geometry of population responses in visual cortex. Nature, 571(7765), 361365. doi:10.1038/s41586-019-1346-5

Stringer, C., Pachitariu, M., Steinmetz, N., Reddy, C. B., Carandini, M., \& Harris, K. D. (2019). Spontaneous behaviors drive multidimensional, brainwide activity. Science, 364(6437), 255. doi:10.1126/science.aav7893

Sumner, P., Tsai, P. C., Yu, K., \& Nachev, P. (2006). Attentional modulation of sensorimotor processes in the absence of perceptual awareness. Proc Natl Acad Sci U S A, 103(27), 10520-10525. doi:10.1073/pnas.0601974103

Suzuki, S., \& Grabowecky, M. (2003). Attention during adaptation weakens negative afterimages. J Exp Psychol Hum Percept Perform, 29(4), 793-807. doi:10.1037/00961523.29.4.793

Tegmark, M. (2016). Improved Measures of Integrated Information. PLoS Comput Biol, 12(11), e1005123. doi:10.1371/journal.pcbi.1005123

Thiele, A. (2013). Muscarinic signaling in the brain. Annu Rev Neurosci, 36, 271-294. doi:10.1146/annurev-neuro-062012-170433

Tononi, G. (2004). An information integration theory of consciousness. BMC Neurosci, 5, 42. doi:10.1186/1471-2202-5-42

Tononi, G., Boly, M., Massimini, M., \& Koch, C. (2016). Integrated information theory: from consciousness to its physical substrate. Nat Rev Neurosci, 17(7), 450-461. doi:10.1038/nrn.2016.44

Tononi, G., Srinivasan, R., Russell, D. P., \& Edelman, G. M. (1998). Investigating neural correlates of conscious perception by frequency-tagged neuromagnetic responses. Proc Natl Acad Sci U S A, 95(6), 3198-3203. doi:10.1073/pnas.95.6.3198

Travis, S. L., Dux, P. E., \& Mattingley, J. B. (2019). Neural correlates of goal-directed enhancement and suppression of visual stimuli in the absence of conscious perception. Atten Percept Psychophys, 81(5), 1346-1364. doi:10.3758/s13414-018-1615-7

Tsuchiya, N., \& Koch, C. (2014). On the relationship between consciousness and attention: MIT Press.

Tsuchiya, N., \& Koch, C. (2016). Chapter 5 - The Relationship Between Consciousness and TopDown Attention. In S. Laureys, O. Gosseries, \& G. Tononi (Eds.), The Neurology of Consciousness. Cognitive Neuroscience and Neuropathology (Second Edition ed., pp. 71 91): Academic Press.

Tsuchiya, N., \& Saigo, H. (2020). Applying Yoneda's lemma to consciousness research: categories of level and contents of consciousness.

Tsuchiya, N., Taguchi, S., \& Saigo, H. (2016). Using category theory to assess the relationship between consciousness and integrated information theory. Neuroscience research, 107, 1-7.

Tsuchiya, N., Wilke, M., Frassle, S., \& Lamme, V. A. F. (2015). No-Report Paradigms: Extracting the True Neural Correlates of Consciousness. Trends Cogn Sci, 19(12), 757-770. doi:10.1016/j.tics.2015.10.002 
Tversky, A. (1977). Features of similarity. Psychological review, 84(4), 327.

vanBoxtel, J. J., Tsuchiya, N., \& Koch, C. (2010a). Consciousness and attention: on sufficiency and necessity. Front Psychol, 1, 217. doi:10.3389/fpsyg.2010.00217

vanBoxtel, J. J., Tsuchiya, N., \& Koch, C. (2010b). Opposing effects of attention and consciousness on afterimages. Proc Natl Acad Sci U S A, 107(19), 8883-8888. doi:10.1073/pnas.0913292107

vanKempen, J., Gieselmann, M. A., Boyd, M., Steinmetz, N. A., Moore, T., Engel, T., \& Thiele, A. (2020). Top-down coordination of local cortical state during selective attention. bioRxiv.

VanRullen, R. (2016). Perceptual cycles. Trends in cognitive sciences, 20(10), 723-735.

Varela, F. J. (1996). Neurophenomenology: A methodological remedy for the hard problem. Journal of consciousness studies, 3(4), 330-349.

Vialatte, F. B., Maurice, M., Dauwels, J., \& Cichocki, A. (2010). Steady-state visually evoked potentials: focus on essential paradigms and future perspectives. Prog Neurobiol, 90(4), 418-438. doi:10.1016/j.pneurobio.2009.11.005

Volz, L. J., \& Gazzaniga, M. S. (2017). Interaction in isolation: 50 years of insights from split-brain research. Brain, 140(7), 2051-2060. doi:10.1093/brain/awx139

Watanabe, M., Cheng, K., Murayama, Y., Ueno, K., Asamizuya, T., Tanaka, K., \& Logothetis, N. (2011). Attention but not awareness modulates the BOLD signal in the human V1 during binocular suppression. Science, 334(6057), 829-831. doi:10.1126/science.1203161

Webb, T. W., Igelstrom, K. M., Schurger, A., \& Graziano, M. S. (2016). Cortical networks involved in visual awareness independent of visual attention. Proc Natl Acad Sci U S A, 113(48), 13923-13928. doi:10.1073/pnas.1611505113

Weil, R. S., Kilner, J. M., Haynes, J. D., \& Rees, G. (2007). Neural correlates of perceptual fillingin of an artificial scotoma in humans. Proc Natl Acad Sci U S A, 104(12), 5211-5216. doi:10.1073/pnas.0609294104

Wilke, M., Mueller, K. M., \& Leopold, D. A. (2009). Neural activity in the visual thalamus reflects perceptual suppression. Proc Natl Acad Sci U S A, 106(23), 9465-9470. doi:10.1073/pnas.0900714106

Woodman, G. F., \& Luck, S. J. (2003). Dissociations among attention, perception, and awareness during object-substitution masking. Psychol Sci, 14(6), 605-611. doi:10.1046/j.09567976.2003.psci_1472.x

Wyart, V., Dehaene, S., \& Tallon-Baudry, C. (2011). Early dissociation between neural signatures of endogenous spatial attention and perceptual awareness during visual masking. Front Hum Neurosci, 6, 16. doi:10.3389/fnhum.2012.00016

Wyart, V., \& Tallon-Baudry, C. (2008). Neural dissociation between visual awareness and spatial attention. J Neurosci, 28(10), 2667-2679. doi:10.1523/JNEUROSCI.4748-07.2008

Zahavi, D., \& Gallagher, S. (2008). The phenomenological mind. London: Routhledge, 244.

Zenon, A., \& Krauzlis, R. J. (2012). Attention deficits without cortical neuronal deficits. Nature, 489(7416), 434-437. doi:10.1038/nature11497

Zhang, F., Wang, L. P., Brauner, M., Liewald, J. F., Kay, K., Watzke, N., . . . Deisseroth, K. (2007). Multimodal fast optical interrogation of neural circuitry. Nature, 446(7136), 633-639. doi:10.1038/nature05744

Zhang, P., Jamison, K., Engel, S., He, B., \& He, S. (2011). Binocular rivalry requires visual attention. Neuron, 71(2), 362-369. doi:10.1016/j.neuron.2011.05.035 
Figure 1

a)

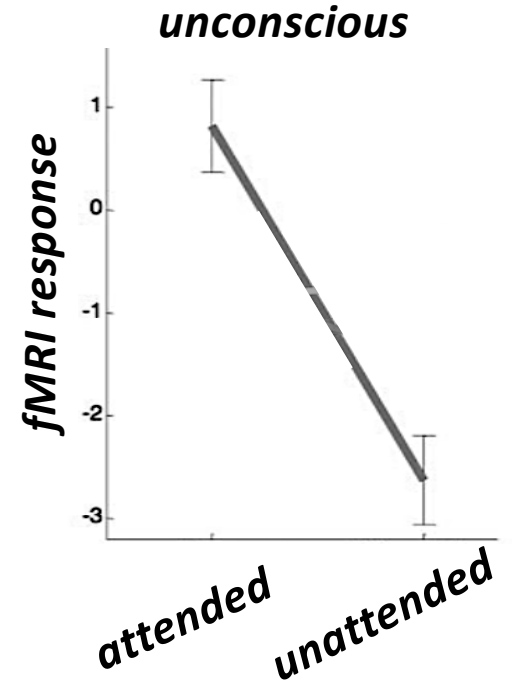

b)

b)

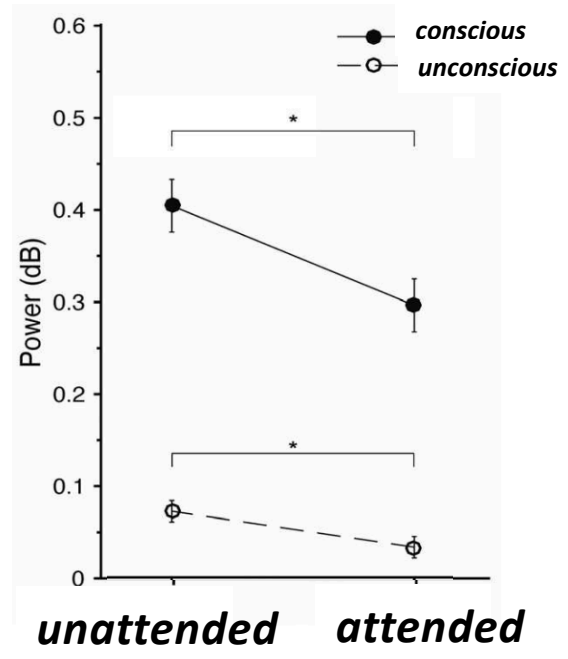

c)

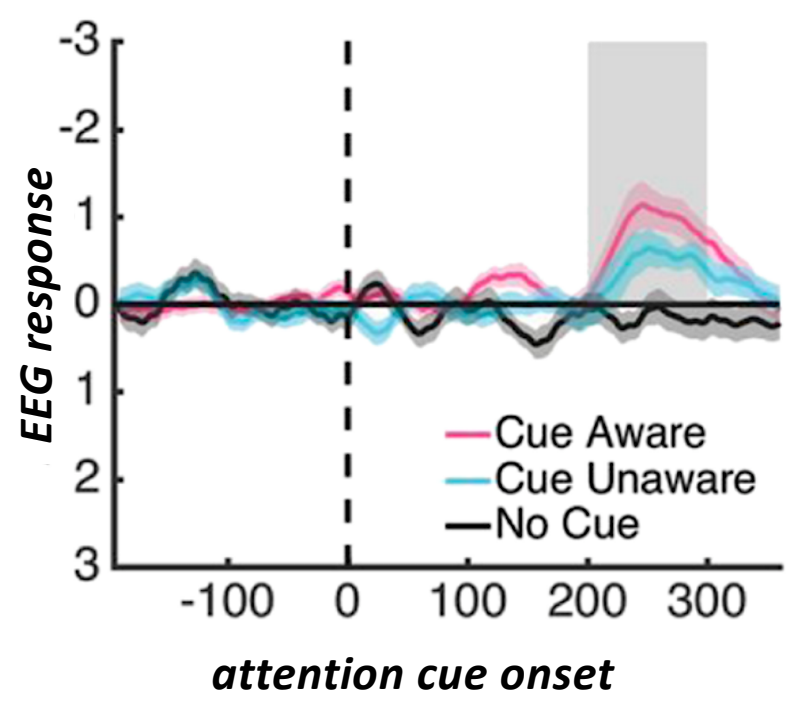


Figure 2

a)

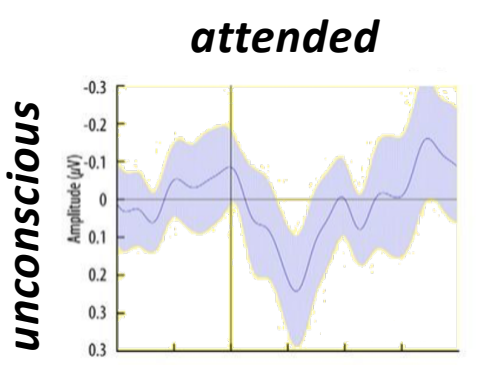

nattended
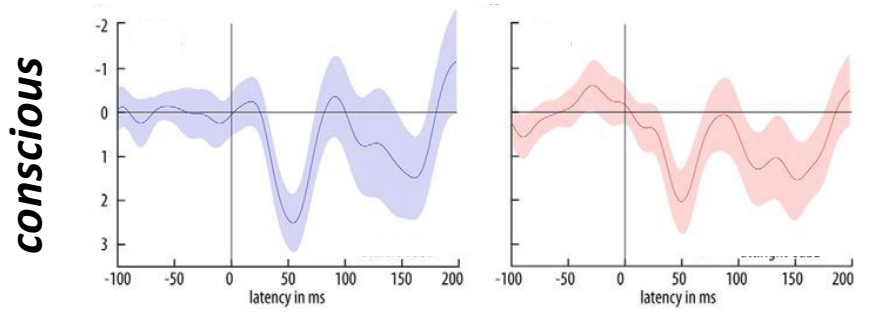

b)

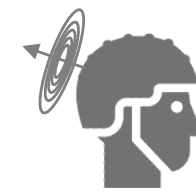

$\omega$

conscious

attended

(no matter attentional state) (no matter conscious state)
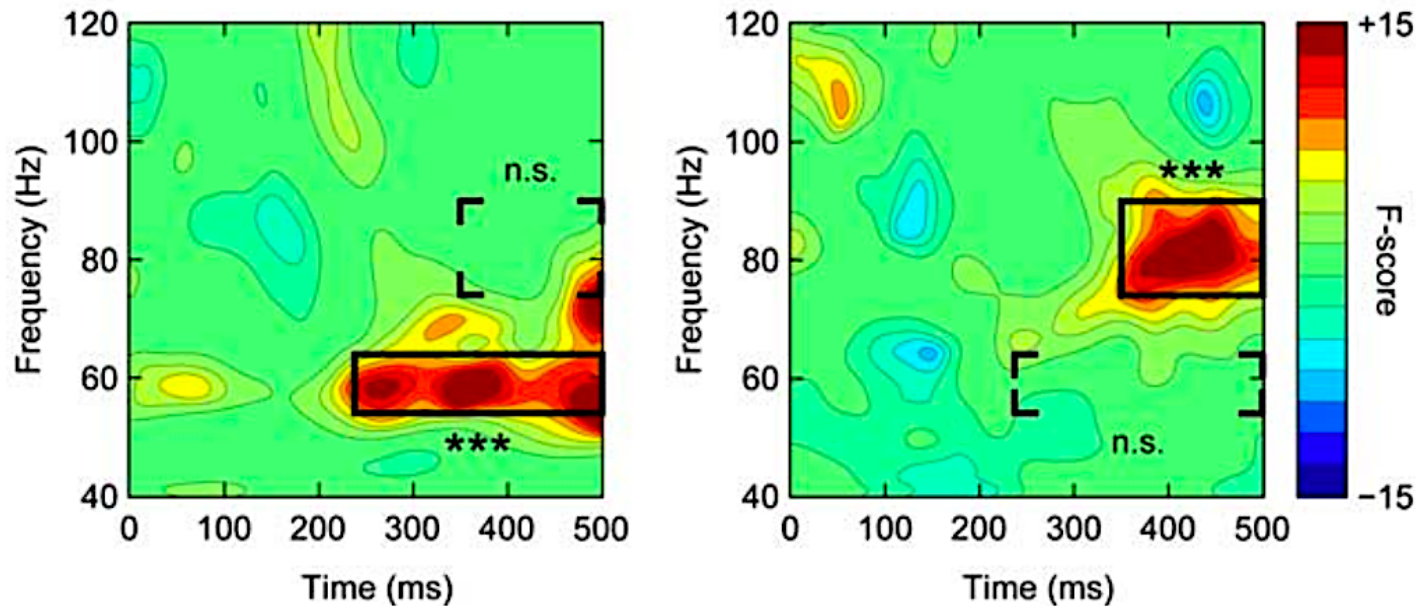
Figure 3

a)

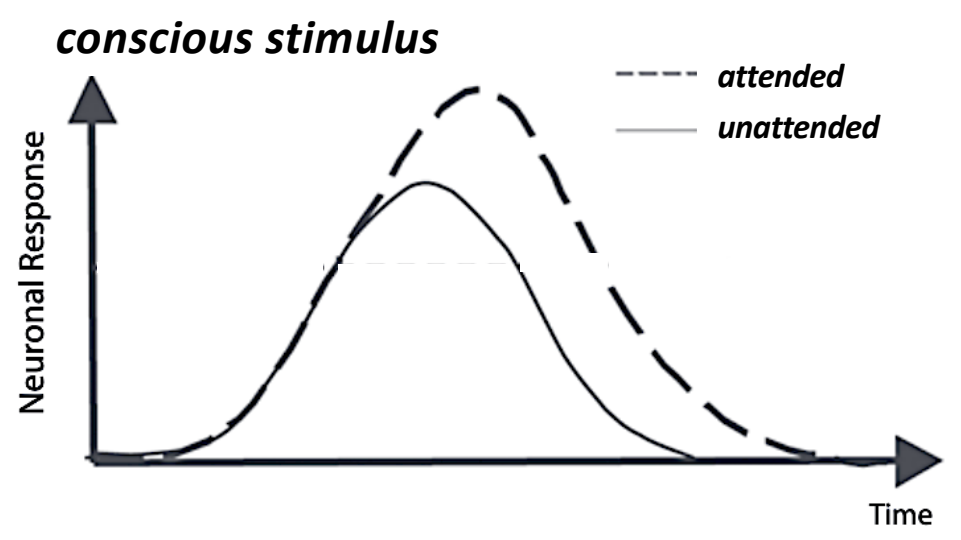

unconscious stimulus

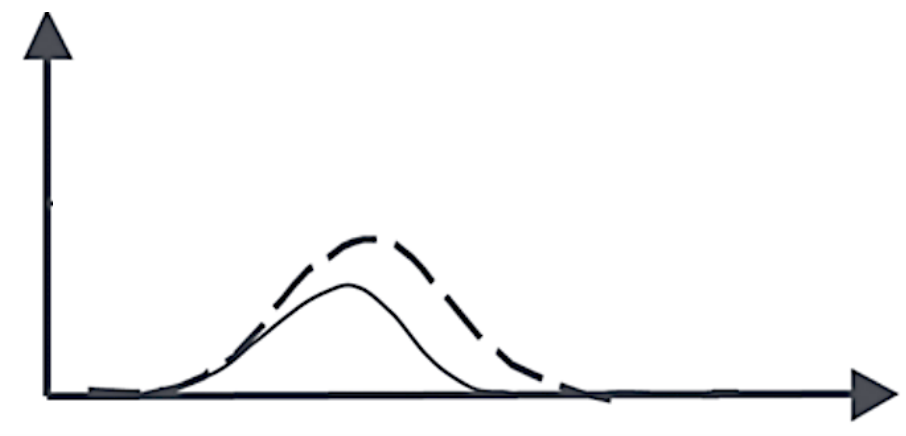

b)
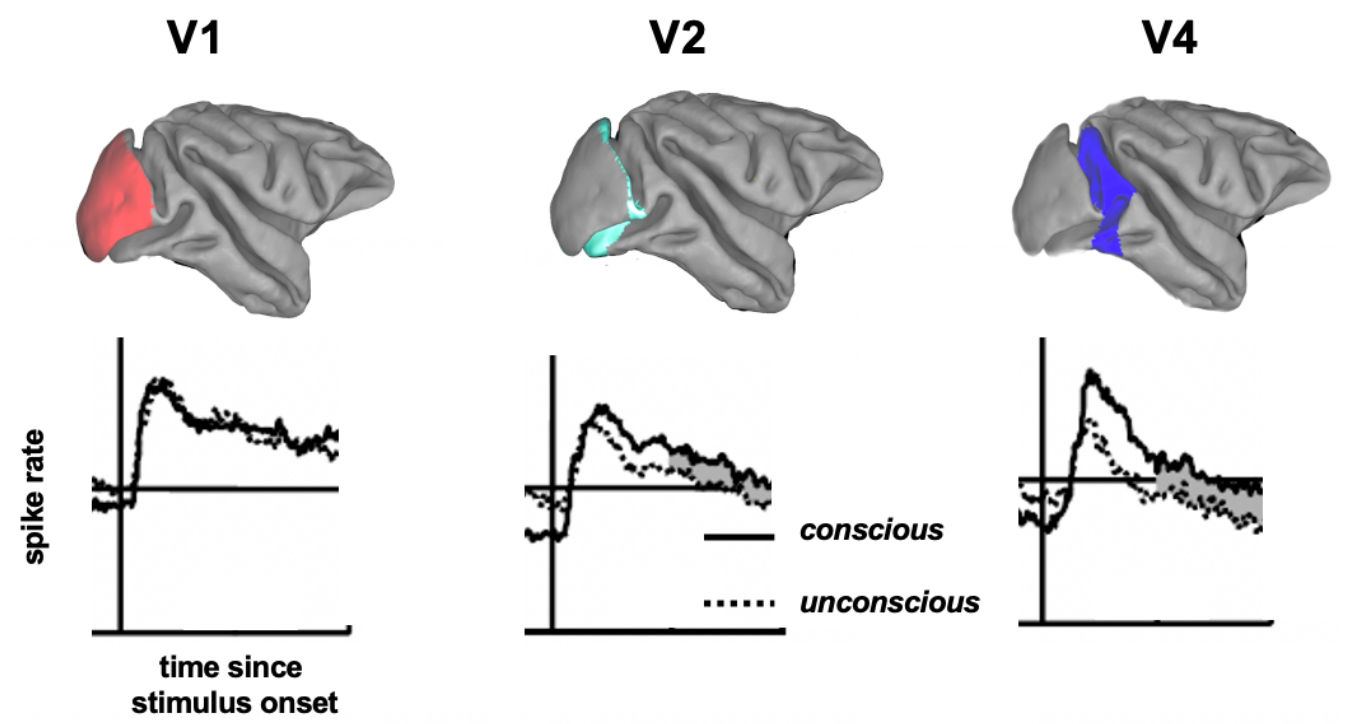

stimulus onset
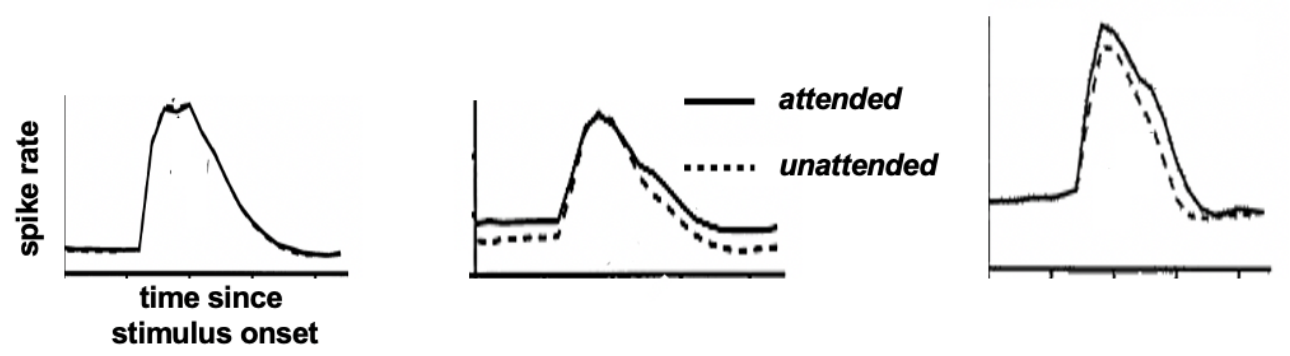
Figure 4

a)

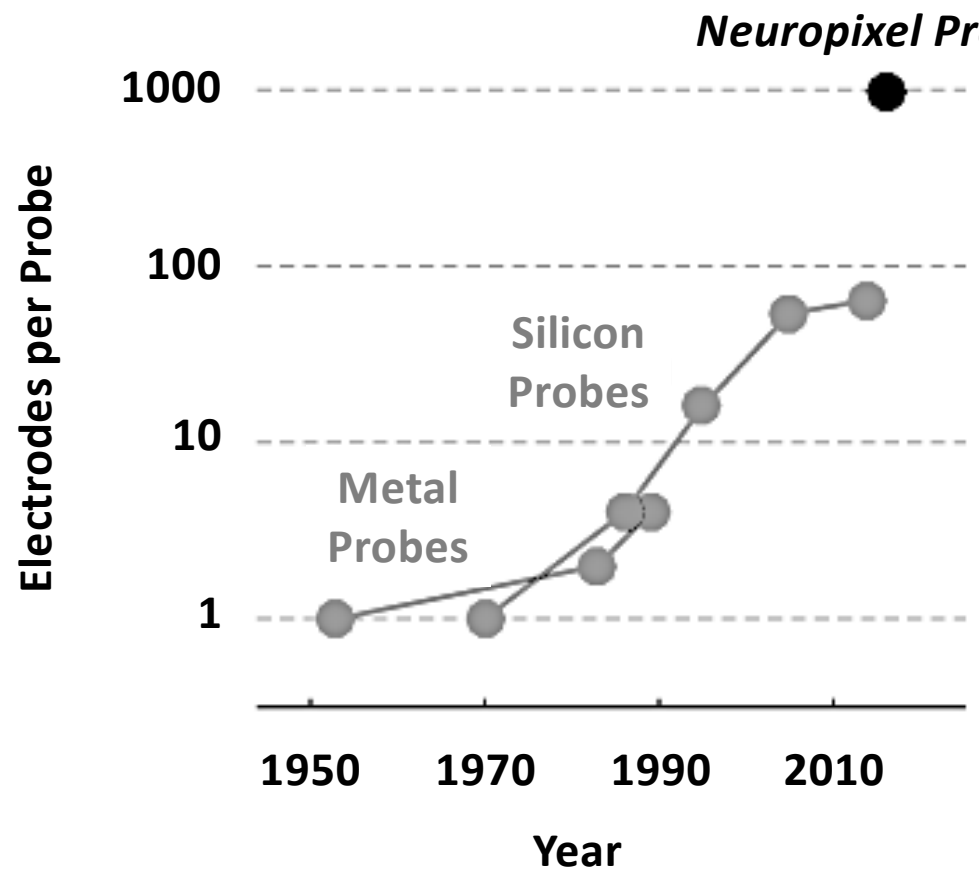

b)
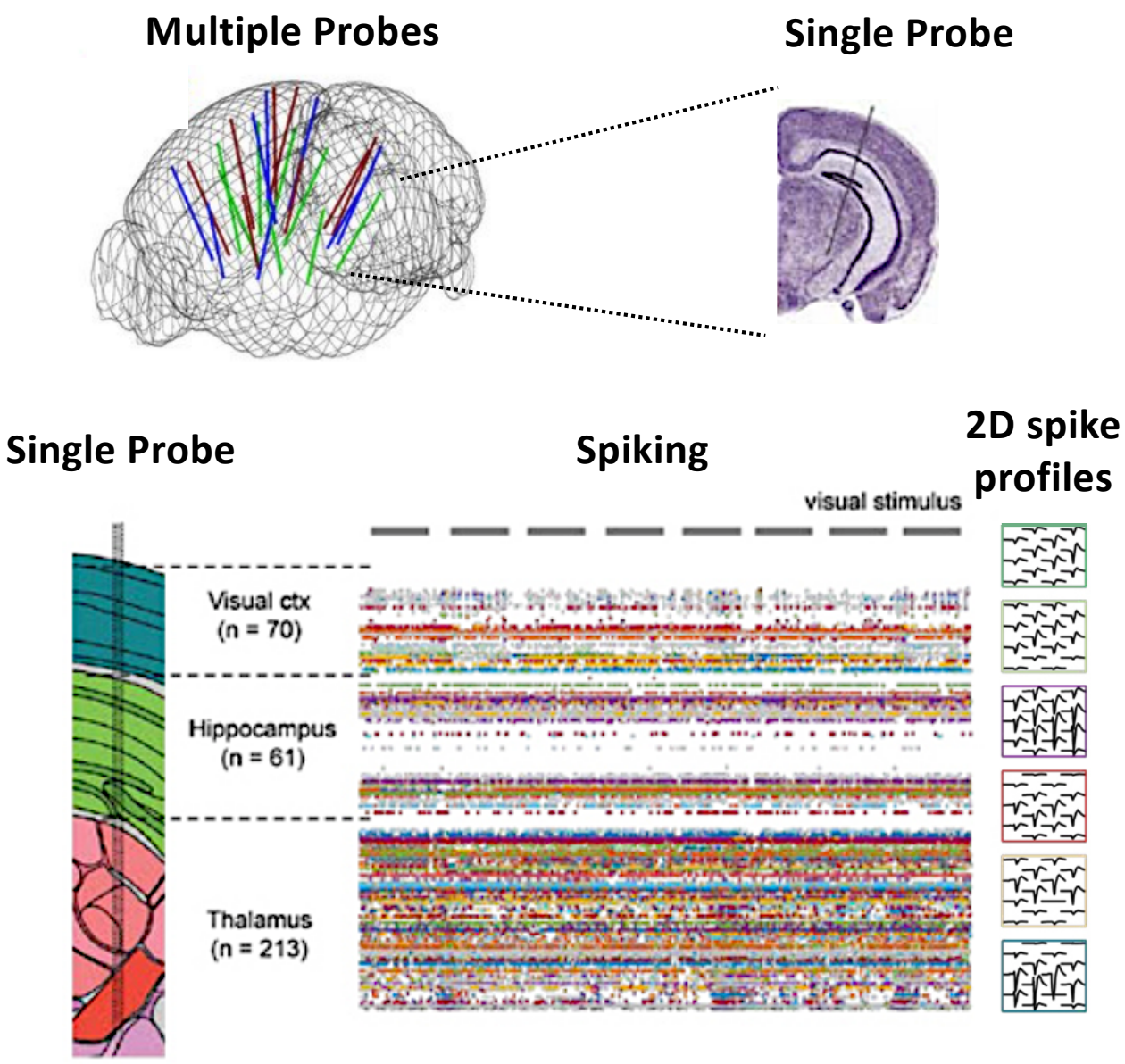
Figure 5

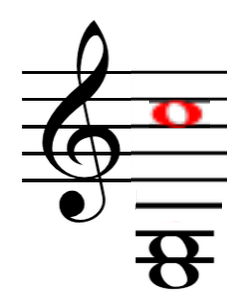

vS.

$\frac{0}{\frac{\theta}{\frac{\theta}{8}}}$

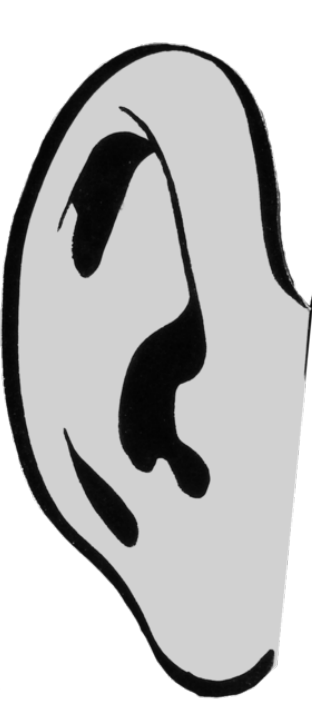

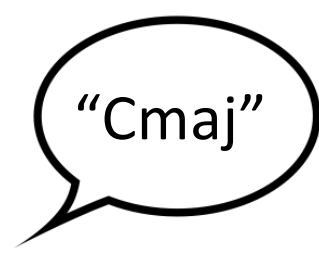
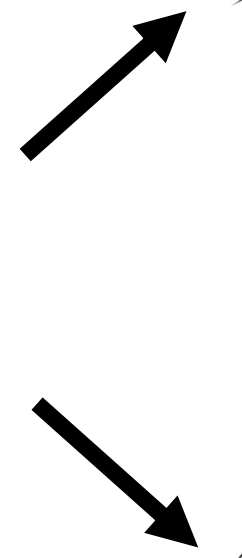

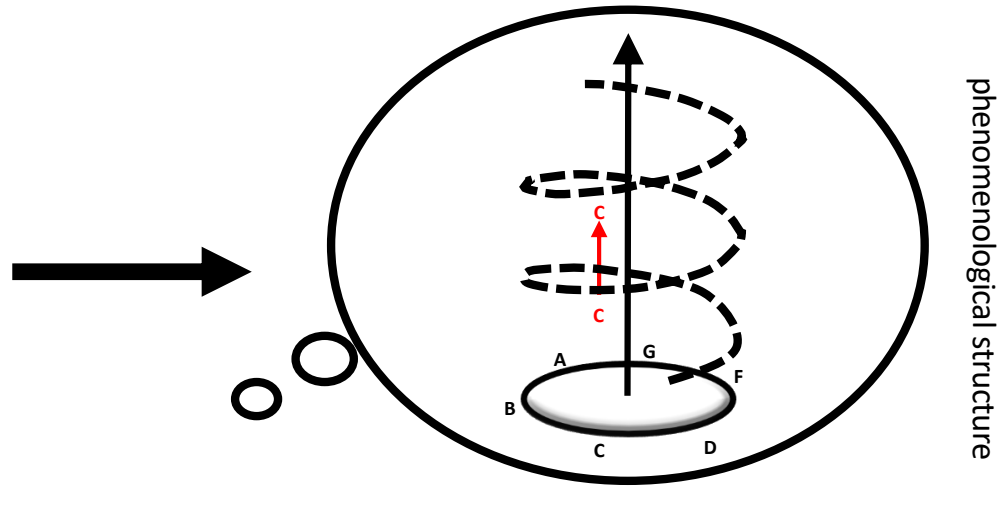

isomorphism?

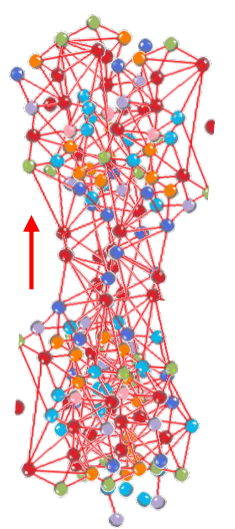

